\title{
Espacios de Contienda Política: las movilizaciones de 2011 en Barcelona y Madrid contra la crisis económica
}

\author{
Emanuel BRAN GUZMÁN \\ Máster en Sociología \\ Universidad de Barcelona \\ emasgt@gmail.com
}

Recibido: 17-10-2012

Aceptado: 28-03-2013

\section{RESUMEN}

El análisis del conflicto social, desde la perspectiva de la Contienda Política implica ubicar ciertos mecanismos causales para explicar, en parte, el accionar de los movimientos sociales. Dentro de esta corriente hay quienes apuestan por entender el papel que juega el espacio dentro de la contienda política (por ejemplo, Tilly, Sewell, Marston o Martin y Miller), lo cual les ha llevado a concebirlo como un elemento fundamental y constituyente de lo social. Charles Tilly propondrá un modelo explicativo para integrar dimensiones espaciales y mecanismos. El presente trabajo analiza el movimiento social denominado $15-\mathrm{M}$, el cual emergió durante uno de los momentos más agudos de la crisis económica en España (2011), en cuanto a la relación dialéctica entre la ocupación de las plazas públicas que protagonizaron como forma de protesta en Madrid y Barcelona y la contienda política.

Palabras clave: crisis; contienda política; apropiación del espacio público; movimientos sociales; movimiento indignado $15-\mathrm{M}$.

\section{Spaces of Contention Politics: protests against the economic crisis in Madrid and Barcelona in 2011}

\begin{abstract}
The analysis of social conflict from the perspective of the Contention Politics means to locate certain causal mechanisms to explain, in part, the actions of social movements. Within this stream there are those who are committed to understanding the role played inside the political contention (e.g., Tilly, Sewell, Marston, or Martin and Miller), which has led them to think of it as an essential and constituent element of the social. Charles Tilly proposes an explicative model in order to better integrate spatial dimensions with mechanisms. This work analyzes the social movement called 15-M, emerged along one of the harshest moments of the economic crisis in Spain (2011) in terms of the dialectic relationship between the squares occupations in Madrid and Barcelona as main form to protest an political contention.
\end{abstract}

Key words: crisis; contention politics; occupation of public space; social movements; indignants movement $15-\mathrm{M}$. 


\title{
Espaço de confronto político: as mobilizações de 2011 em Barcelona e Madri contra a crise econômica
}

\begin{abstract}
RESUMO
A análise do conflito social a partir da perspectiva do confronto político implica localizar certos mecanismos causais para explicar, em parte, a ação dos movimentos sociais. Dentro desta corrente há aqueles que apostam em entender o papel do "espaço" dentro do confronto político (por exemplo, Tilly, Swell, Marston ou Martin e Miller), o que os levou a concebê-lo como um elemento fundamental e constituinte do social. Charles Tilly proporá um modelo explicativo para integrar dimensões espaciais e mecanismos. O presente trabalho analisa o movimento social denominado $15-\mathrm{M}$, que emergiu durante um dos momentos mais agudos da crise econômica na Espanha (2011), no que diz respeito à relação dialética entre a ocupação das praças públicas que protagonizaram como forma de protesto em Madri e Barcelona e o confronto político.
\end{abstract}

Palavras-chave: crise; confronto político; apropriação do espaço público; movimentos sociais; movimento indignado $15-\mathrm{M}$.

\section{REFERENCIA NORMALIZADA}

Bran Guzmán, Emanuel (2012) "Espacios de Contienda Política: las movilizaciones de 2011 en Barcelona y Madrid contra la crisis económica". Geopolítica(s). Revista de estudios sobre espacio y poder, vol. 3, núm. 2, 235-270.

SUMARIO: Introducción. 1. Antecedentes de la indignación y la movilización. 2. Espacialidad y contienda política: nuevas posibilidades en el análisis de los movimientos sociales. 3. El surgimiento del 15-M: identidades, repertorios y simbolismo en disputa. Conclusión. Bibliografía.

\section{Introducción}

La crisis económica mundial que inició en el 2008 impactó en España contundentemente. El retroceso en las garantías del Estado de bienestar provocadas por la implementación de ajustes en la economía local activó entre el 2010 y 2011 la protesta y movilización social, aunque esta vez dos cuestiones harían la diferencia con anteriores formas de movilización, por un lado, la ocupación de las plazas públicas como forma de protesta, y por otro, un movimiento ciudadano distinto a los viejos y nuevos movimientos sociales hasta ahora conocidos. Dicho movimiento, conocido como "indignados" o "15-M", ocupó una buena cantidad de plazas en todo el Estado español y movilizó la protesta social contra la crisis y sus responsables, esto le catapultó en poco tiempo hacia la arena política nacional e internacional ${ }^{1}$.

\footnotetext{
${ }^{1}$ El 19 de mayo del 2011 una foto de la Puerta del Sol ocupaba la primera plana del Washington Post con el siguiente título: A SPRING OF FRUSTRATION IN SPAIN.
} 
Muchas de las reflexiones que desencadenó el 15-M (entre el 2011 y 2012) se centraron en su organicidad y demandas, o bien en su impacto político y cultural. En ningún caso que conozcamos se hace una valoración sobre la relación entre espacio y protesta social, aspecto relevante para un movimiento que revitalizó la ocupación como repertorio de lucha. Esto nos llevó a preguntarnos ¿de qué manera influyó la apropiación del espacio público en el desarrollo de la contienda política durante las movilizaciones del 2011 contra la crisis económica? En la búsqueda de una respuesta nos acercamos a dos propuesta teóricas, por un lado la Dinámica de la Contienda Política (DOC, por sus siglas en inglés), la cual ha teorizado sobre movimientos sociales y trasladado la discusión sobre su accionar e impacto al terreno de lo que han llamado "contienda política", y, por otro, al de la geografía política y/o humana y su énfasis en considerar la naturaleza y rol del espacio en la sociedad. Con la idea de encontrar una propuesta integradora, de algunos aspectos de ambas corrientes, nos centramos en el trabajo de Charles Tilly (2000; 2003), quien propone integrar las dimensiones espaciales (tiempo-distancia, proximidad, movilidad y significado) en la explicación de la Contienda Política.

La hipótesis con la que encaramos este trabajo la formulamos en los siguientes términos: las configuraciones espaciales adoptadas en los espacios ocupados por el movimiento 15-M influyeron en el desarrollo de la contienda política durante las movilizaciones contra la crisis en el 2011, especialmente en que: 1) la ampliación y conexión del movimiento indignado a nivel del Estado influyó en la creación de identidades difusas y genéricas; 2) las dimensiones espaciales de la contienda incidieron en la utilización de determinados repertorios de acción adoptados por el movimiento 15-M; y 3) la re-significación política de los espacios ocupados posibilitó la permanencia del movimiento y sirvió para volcar la contienda a su favor.

En cuanto a lo metodológico, el artículo que presentamos a continuación partió de una perspectiva comparativa de "sistemas más diferentes", tomando en cuenta casos cercanos y maximizando la comparabilidad (McAdam, Tarrow y Tilly, 2005), y dentro de ésta, un enfoque de "bases comunes". Los casos analizados fueron las ocupaciones de la "Puerta del Sol" en Madrid y la "Plaça Catalunya" en Barcelona por el movimiento 15-M entre mayo y junio del 2011. Ambos casos comparten unas bases comunes definidas por las características de un "ciclo político", el cual es descrito en los siguientes apartados ${ }^{2}$. Como complemento incluimos algunas de las

\footnotetext{
${ }^{2}$ Podemos adelantar que ambos casos experimentaron un decaimiento en la movilización de carácter masivo durante el primer sub-ciclo político. Eso se vio complementado por cierta permisividad para el accionar de los movimientos. En ambos casos se dio la presencia de colectivos y redes. Posteriormente, en la medida en que avanzaba el segundo sub-ciclo y la crisis económica acaparaba la atención social, se vivió un ambiente creciente de movilización. En medio de todo esto, las "Revoluciones árabes" y lo sucedido en Islandia fue el telón de fondo internacional que las dos ocupaciones compartieron y que de alguna manera marcó el discurso inicial de movilización durante aquel mes de mayo del 2011.
} 
acciones más relevantes del 15-M entre junio y octubre de ese mismo año, dado que forman parte del corolario de las ocupaciones. El hecho de situarnos en este espacio temporal respondió a nuestro interés por pensar en lo sucedido durante las ocupaciones de las plazas, en reflexionar sobre la ocupación del espacio público y su relación con la contienda política.

Para recabar el material empírico utilizamos dos tipos de fuentes. El primero corresponde a material documental que nos permitió conocer el movimiento $15-\mathrm{M}$ en dos sentidos: el ciclo político que le antecedió y aquellos hechos que recogen la dinámica de la contienda política, especialmente durante la ocupación de las plazas. La elección de la noción de "ciclo político" nos permitió establecer los antecedentes de lo que hemos llamado la emergencia de la indignación y movilización. El segundo tipo de fuente, lo conforman once entrevistas semiestructuradas de activistas de Barcelona y Madrid. El perfil de los entrevistados es el siguiente: 4 mujeres y 7 hombres, todos ellos entre 25 y 40 años, con diferentes experiencias de militancia e involucrados en el 15-M con funciones y cargos diversos. Su selección respondió a incluir la mayor diversidad posible de experiencias, aunque cabe aclarar que esto se vio limitado por el momento en el cual se realizó el trabajo de campo. La técnica de entrevista utilizada nos permitió valorar dicha diversidad y el sentido de la experiencia relacionada al 15-M, además, recoger el contexto en que ésta ocurrió y colocar la acción humana como punto central del análisis (Blee y Taylor, 2002).

Para el tratamiento de la información nos hemos valido del "Método de Comparación Constante" (MCC) de que desarrollaron Glaser y Strauss en $1967^{3}$, base fundamental de la "Grounded Theory". Sabiendo de antemano el potencial del MCC para la generación de teoría a partir del análisis comparativo y sistemático de información empírica (Trinidad, Carrero y Soriano, 2006; Andréu, García-Nieto y Pérez, 2007), nos limitamos a usarlo como método para conectar la información proveniente de las entrevistas con nuestro planteamiento teórico. Para realizar este proceso partimos de tres ejes de comparación: 1) potenciación de redes y nuevas identidades; 2) creación, resignificación y difusión de repertorios; y 3) resignificación política del espacio y actividad contenciosa.

\section{Antecedentes de la indignación y la movilización}

Pensar un movimiento como el 15-M implica, forzosamente, conocer los antecedentes o "el clima" que ha rodeado su emergencia y desarrollo, esto es, ubicar el mo-

\footnotetext{
${ }^{3}$ De manera general las fases del MCC comprenden: 1) identificación de incidentes (identificados en documentos, entrevistas, etc.); 2) creación de conceptos y codificación; 3) integración de categorías y propiedades; 4) conceptualización teórica; y 5) escritura de la teoría (Trinidad, Carrero y Soriano, 2006; Andréu, García-Nieto y Pérez, 2007).
} 
vimiento en las condiciones definidas por el "ciclo político" del que forma parte. Dicho "ciclo político" es "un periodo de tiempo relativamente unificado por el actor o coalición de actores que hegemonizan el poder o la autoridad o ambas cosas y que sobre esta base, directa e indirectamente, definen unas reglas del juego (incluso los componentes principales de la cultura política operativa) para la interacción de todas los actores en presencia" (Aguilar et al., 2003: 57-58).

Todo ciclo político combina al menos tres elementos: institucionales, estratégicos y simbólicos. Y su operativización viene dada por una serie de indicadores:

El clima general de mayor o menor liberación política operativa y los valores de mayor y menor permisividad (...) El clima con respecto a las políticas públicas que dominan el periodo, muy vinculadas al tipo de fuerza política (socialdemócrata, de derecha liberal, de derecha arcaica) que controla el Estado y [sus] objetivos (...) Las estrategias de orden que manejan las autoridades (...) [y] las alianzas que dominan entre las fuerzas sociales y políticas (Aguilar et al., 2003: 93).

En una investigación realizada sobre la nueva sociedad civil española, Aguilar et al. (2003) relacionan la noción de ciclo político y la de estructura de oportunidades políticas (EOP) para analizar los diferentes sistemas y ciclos políticos que rodearon la protesta social durante y después de la transición política española. Establecen tres ciclos políticos entre 1976 y el $2003^{4}$. Este artículo propone indagar, como punto de partida, sobre un cuarto ciclo político, el que marca el retorno del Partido Socialista Obrero Español (PSOE) al gobierno (2004-2011) y sirve de antecedente para entender al 15-M. De manera general, este ciclo se subdivide en dos momentos o subciclos: 1) del 2004 al 2007, durante el cual se expresa un gobierno con una cara más social y que anticipa alguna de las condiciones políticas y sociales que definen el espacio público en el que se desarrollará el 15-M; y 2), del 2008 al 2011, que estará influenciado de principio a fin por la crisis económica mundial y es propiamente el espacio temporal en el que cuajan las condiciones políticas, sociales y económicas de la situación de crisis y donde emerge el 15-M.

\subsection{El ciclo político 2004-2011: política social y crisis económica}

El primer punto que queremos destacar de este subciclo tiene que ver con la victoria electoral del PSOE en el 2004, especialmente la imagen de cambio que ello repre-

\footnotetext{
${ }^{4}$ Estos son: 1) "el ciclo de la transición" (1976-1982), que incluye tanto su preparación como resolución; continúa con 2) "el ciclo político social demócrata" (1982-1996), el cual es hegemonizado por el PSOE; y termina con 3) "el ciclo político conservador" (1996-2003), controlado por el Partido Popular (Aguilar et al., 2003: 95-96).
} 
sentaba al tiempo que confirmaba la tendencia del sistema político español desde la transición: el bipartidismo entre el PSOE y el PP. El segundo de los puntos a destacar tiene que ver con las políticas, medidas o leyes que impulsó el PSOE y el presidente Zapatero durante este periodo. Todas ellas aprobadas en la primera legislatura $\mathrm{y}$ tendientes a beneficiar a diversos grupos sociales y a incorporar viejas reivindicaciones. Esto afianzó simpatías, forjó alianzas y provocó el rechazo de la oposición tradicional y conservadora ${ }^{5}$.

Otro punto importante fue la alianza en el mundo del trabajo entre el PSOE, los sindicatos (UGT, CCOO) y la patronal, la cual trajo consigo un aumento del salario interprofesional y un proceso incipiente de negociaciones para lograr una nueva reforma laboral. En el 2007 Zapatero celebraba así los acuerdos: el "dialogo social impulsado durante esta legislatura con las organizaciones empresariales y sindicales ha posibilitado el periodo más largo de «paz social desde la Transición democrática», ya que ha sido la etapa «donde menos horas de trabajo se han perdido por huelgas desde 1977»" (El Economista.es, 23/10/ 2007).

En general, en este subciclo se dio una mayor "liberalización" política y un mayor ambiente de "permisividad", todo ello expresado en políticas concretas y leyes. Podríamos decir que estas fueron indicadores de homogeneidad política y representaron el ideario y los valores socialdemócratas del PSOE. Este "clima" abrió "oportunidades para la acción política" (Aguilar et al., 2003), especialmente para aquella vinculada a la política institucional. En cuanto a las alianzas, existió una clara diferencia con el PP, el PSOE se alió informalmente con los partidos a su izquierda en aquellos puntos de encuentro que permitieron la confluencia (Navarro, 2011).

En las elecciones del 2008 el PSOE, nuevamente con Zapatero a la cabeza, sale vencedor, aunque esta vez necesitaría del apoyo de otros partidos para sacar adelante sus proyectos. Desde un inicio la agenda política del PSOE se vio desplazada por lo que sería la preocupación y punto fundamental de este periodo: la crisis económica. La forma de afrontarla tuvo inicialmente un carácter internacional, tanto en las acciones como en la forma en que se entendía y se trasladaba a la población. Sin embargo, lo que a finales del 2007 la clase política consideraba una crisis internacional, en el 2009 no podía ya ocultar sus raíces locales: "la caída de los promotores inmobiliarios, el espectacular aumento del paro y el descenso general de la actividad económica" (Observatorio Metropolitano, 2011: 14-15).

Las medidas adoptadas para afrontar la crisis tuvieron un importante impacto en la escena política y social. Por un lado, acrecentaban la idea en la sociedad de que el

\footnotetext{
${ }^{5}$ Las viejas reivindicaciones: la Ley de dependencia o Ley de Autonomía Personal en 2006 ("el cuarto pilar del Estado de bienestar" según Zapatero) (El Pais, 03/04/2011). Leyes o medidas que granjearon las alianzas: la derogación del trasvase del Ebro en 2004 y su apoyo al ecologismo ("Los hitos políticos de Zapatero", Publico.es, 02/04/2011). La discordia: El divorcio exprés y el matrimonio homosexual en 2006 ("Retrato de un presidente en 20 Leyes", El País, 03/04/2011).
} 
destino de España se decidía en Bruselas, por otro, implicaron un retroceso en lo realizado en el periodo anterior, además del fortalecimiento de la oposición y el desgaste de las alianzas del PSOE ${ }^{6}$.

En medio de esto, el conflicto político adoptaba una forma pacífica y pactada - por lo menos dentro de los espacios de política institucional así es como se viene resolviendo- - . Una de las medidas de ajuste, la de aumentar la edad de jubilación hasta los 67 años la edad, conllevó advertencias, huelgas parciales y el llamado a una huelga general el 23 de septiembre del 2010 por parte de los sindicatos mayoritarios. En contrapartida el PSOE decidió llevar la propuesta de reforma laboral al Congreso. Finalmente, a inicios del 2011, el gobierno y los sindicatos logran "un principio de acuerdo" (El País, 27/01/2011). Esto supuso la reconciliación del PSOE con los sindicatos, la recuperación del liderazgo de Zapatero y el cumplimiento ante la UE y el FMI. Los medios de comunicación escrita lo celebraron como un "acuerdo histórico" (El País, 28/01/2011), como "un acuerdo trascendental" (La Vanguardia, 28/01/2011). En medio de la crisis supuso un respiro: "refuerza al Ejecutivo - particularmente Zapatero- y legitima la labor negociadora de UGT y Comisiones Obreras" (El País, 28/01/2011) y representa "un anhelado consenso entre las partes, lo que es de celebrar por cuanto supone evitar tensiones sociales en una etapa económica de grave y larga crisis" (La Vanguardia, 28/01/2011).

En general, se da una homogeneidad política marcada por un alineamiento del PSOE con las políticas de la UE y el Fondo Monetario Internacional. El clima de "permisividad" y "liberalismo" se difuminaría en la medida en que avanzaban los ajustes, se daba marcha atrás en ciertas medidas de la primera legislatura y el rechazo alimentaba la protesta, en sintonía con ello, las alianzas se fueron deteriorando. Ha sido, pues, un subciclo político marcado por la crisis y las medidas de clara tendencia neoliberal.

\subsection{Protesta social en Madrid y Barcelona entre 2004 y 2011: de la denuncia aislada a la movilización y la articulación}

Las acciones de movilización y de protesta dentro del ciclo político tienen que ver, sobre todo, con aquellas impulsadas por colectivos, grupos de interés, sindicalismo

\footnotetext{
${ }^{6}$ Durante el primer semestre del 2010 el gobierno incrementa el IVA hasta el 18\% a pesar de la oposición del resto de partidos (El Economista.es, 16/03/2010). Tiempo después, tal como lo indicaba la Unión Europea UE, impulsa "las medidas de ajuste del gasto y reducción del déficit público". Especialmente en estas últimas medidas el PSOE actuó en solitario. Las críticas eran abanderadas por casi todos los partidos, los argumentos reclamaban que las medidas habían sido impuestas desde la UE, que se centraban en los más débiles y que no llevarían a salir de la crisis (Tv Cuatro, 12/05/2010).
} 
independiente y otros colectivos similares. Al analizarlas no lo hacemos pensando en que están dentro de un "ciclo de protesta" (Tarrow, 2002) u "ola de movilización" (Aguilar, 2008a) determinada7. Lo hacemos destacando el tipo de acción y su relación con las "reglas del juego" definidas dentro del ciclo político.

Este ciclo se caracteriza por un descenso en las acciones de protesta y movilización, tan contundente y masivas tan solo unos años atrás (Pradel et al., 2004; Bringel et al., 2006). Entender este descenso pasa por tomar en cuenta varias cuestiones: "el fin del referente movilizador que podría sintetizar el periodo anterior: el «Anti PP»"; "el cansancio después de un ciclo muy largo" y "la falsa impresión de «victoria», el famoso lo conseguimos en relación al cambio de gobierno" (López et al., 2005: 2). Lo mismo se podría decir de las políticas de gobierno, su papel en amortiguar el descontento y la movilización social (Bringel et al., 2006).

Al tiempo que se da la pérdida de masividad y espectacularidad en las acciones se aprecia un paso al trabajo colectivo, en red y centrado en temas precisos. Es en este momento de latencia (Melucci, 1994) cuando "resurgen algunos repertorios clásicos menos ensayados en el período previo" (López et al., 2005); cuando se habla de construir espacios auto gestionados y sin mediaciones institucionales para la acción política y social (por ejemplo, la creación de centros sociales como La Tabacalera y el Patio Maravillas en Madrid) (López et al., 2005); y cuando demandas como "Democracia Radical" o el "cuestionamiento profundo de los canales convencionales de la participación política" vertebrarán las acciones de los colectivos (López et al., 2005).

Durante el primer subciclo tres cuestiones resaltan de la relación entre movimiento social y políticas de gobierno. La primera, que a pesar del clima de mayor libertad política y permisividad empieza a darse un descontento entre las organizaciones no conformes con los alcances de las leyes o medidas implementadas. La segunda, se intensifican las demandas y protestas de diferentes colectivos y organizaciones debido a los "impactos del proceso de globalización en las formas de vida urbana", lo que ha llevado a observar una "hibridación de los movimientos antiglobalización y los movimientos urbanos" (Grau e Ibarra, 2007: 3). La tercera, no se logra activar la movilización tal como había ocurrido en el periodo anterior; Bringel et al. (2006) sostiene que ello se debió al aislamiento que sufren los colecti-

\footnotetext{
${ }^{7}$ La noción de "ciclo de protesta" ha servido para identificar periodos concretos de auge y descenso en la movilización social, en ese sentido hay quienes identifican el 2003 como la conclusión del ciclo de protesta global iniciado en Seattle en 1999 (Pradel et al., 2004). Este ciclo, también llamado "anti-globalización", "contra-cumbre" o "altermundista", luego de su contundente capacidad de movilización sería desactivado por la represión estatal (López et al., 2005). En el caso de España, el 2003 también concluye con una serie de movilizaciones (las más emblemáticas: los encierros de "los sin papeles" en 2001, la huelga general en 2002, la movilización del "No a la guerra" en 2003). Este ciclo, a primera vista, da la impresión de haber sido desactivado por los cambios políticos (victoria del PSOE) tras los atentados del 11 de marzo del 2004 (Pradel et al., 2004; Bringel et al., 2006).
} 
vos por parte del gobierno y medios de comunicación (ocupados por la oposición y movilización que la derecha desplegaba).

Ahora bien, con el tiempo, se producirá un incremento en la protesta condicionado por el rechazo a las políticas locales y gubernamentales. La "oportunidad política" (McAdam, McCarthy y Zald, 1999) que esto abre hará resurgir cierta "acción colectiva de masas" (Aguilar et al., 2003) y acciones de protesta de todo tipo. Además, hará cambiar el clima inicial de mayor relajamiento y menor represión para los movimientos sociales por parte de la policía (López et al., 2005, Bringel et al., 2006). Un ejemplo de las nuevas formas de control social revestidas de civismo vendría a ser la Ordenanza Cívica de Barcelona, la cual debe ubicarse en la misma sintonía que las reformas del PP en el 2003, donde la seguridad ciudadana era entendida como "seguridad en las calles" (Andreu, 2006) ${ }^{8}$.

El papel de los medios de comunicación en todo esto fue de suma importancia. Aquellos afines al PSOE pierden interés y no cubren las movilizaciones, al menos no en un principio. Por su parte la derecha incrementa su apoyo a las movilizaciones en contra de leyes y medidas controversiales ${ }^{9}$, así, "el PP moviliza desde sus propios medios (el semanario Alba, el gratuito Ahora)" (López et al., 2005: 4) la protesta. En medio de esto los movimientos sociales empiezan a generar nuevos espacios, redes y luchas utilizando con mucho éxito las nuevas tecnologías de la información y medios contra-informativos (el resurgimiento de medios alternativos activos durante la lucha contra el PP: Nodo50, Rebelión, La Haine o Kaosenlared y la circulación del periódico Diagonal en el Estado y La Directa en Catalunya) (López et al., 2005).

Durante el segundo subciclo político la protesta social se caracterizaría por una alta dosis de denuncia, es el caso del movimiento vecinal (Andreu, 2009); de organización, como en el de la vivienda digna; y de acción directa y protesta, como en el movimiento estudiantil que luchaba contra el "plan Bolonia" (2007-2009). En general, el panorama era de poca articulación. Sin embargo, en la medida en que avanza la crisis y las medidas de ajuste empieza a gestarse un ciclo movilizador que avanza de menor a mayor intensidad y articulación. Mientras la dirigencia del sindicalismo oficial negocia y limita la protesta social, la sociedad civil progresi-

\footnotetext{
${ }^{8}$ Las ordenanzas de convivencia que pretenden regular la mendicidad, la prostitución y venta ambulante en Barcelona. Esto provocó protestas de diferentes colectivos dado que "retalla els drets socials, persegueix la pobresa i elimina la vida al carrer" (Cartel de convocatoria a la manifestación del 22 de diciembre. Plataforma victimas del civismo, 2005). Assumpta Scarp (PSC), la persona que ideó la norma, creía que esta sería "un instrumento «innovador» y eficaz, para actuar ante las nuevas realidades sociales y controlar el abuso que algunos ciudadanos hacen del espacio público" (La Vanguardia, 23/12/2005).

${ }^{9}$ Entre el 2005 y 2007 se contabilizan 22 manifestaciones en contra de las leyes impulsadas. Se creó "una atmósfera de confrontación cuasi-física (con imágenes, en algunos momentos, que recordaban la situación previa a la Guerra Civil)"; más allá del manejo político las protestas trataron de "socializar" "las ideas del nuevo molde neoconservador" (Aguilar, 2008a: 32).
} 
vamente se va identificando con denuncias más generales referidas al modelo económico y los recortes del gobierno. El elemento simbólico de este sub ciclo político es favorable a la movilización: "iQue la crisis la paguen ellos!”, "Tots al carrer".

El elemento institucional y las alianzas son importantes: la victoria del PSOE, sus políticas y sus alianzas influyeron en el accionar de los movimientos sociales, primero diezmándolo, y después, abriendo la oportunidad política para que éstos transitaran de la denuncia aislada a la articulación de la protesta. El elemento estratégico: el control sobre del espacio público y la represión, selectiva primero e indiscriminada después, fueron dos elementos que condicionaron la protesta social. Lo simbólico: los colectivos supieron aprovechar las nuevas tecnologías abriendo canales de comunicación entre diversos grupos y movimientos. Todo ello permitió la organización de la protesta, ser críticos con las medidas progresistas, con las problemáticas locales y, posteriormente, con los recortes. Sobre todo, se debatió públicamente la crisis, la democracia y la política.

Finalmente, la acción directa, manifestaciones, concentraciones y caceroladas se "recuperan" como repertorios de protesta cotidianos entre los movimientos. La difusión en internet, plataformas y redes sociales hacen fluir la información, facilitan la coordinación y hacen posible masificar la protesta. Así las cosas, los primeros meses del 2011 son de mucha actividad. En Madrid movilizaciones "por la dignidad y la justicia social" o en Barcelona por un "rechazo ciudadano a las políticas neoliberales del gobierno de CiU" empiezan a volverse cotidianas (Cortavitarte, 2012).

\section{Espacialidad y contienda política: nuevas posibilidades en el análisis de los movimientos sociales}

Los debates sobre el espacio, nacidos en la geografía y heredados a otras ciencias sociales, han puesto énfasis en el significado que éste tiene y su relación con lo social, y por ende, en el alcance de sus categorías más tradicionales (escala, movilidad, distancia, etc.). Los aportes de autores, en algunos casos bastante dispares, como Lefebvre (1991), Harvey (1998), Giddens (1995), Foucault (1999), Castells (1986), Massey (1994) y Soja (1989), ayudaron a entender el rol y el significado del espacio para la acción humana (Martin y Miller, 2003; Marston, 2003). Así, la noción de espacio como "resultado" de lo social dejó de tener hegemonía y dio paso a pensar en un espacio constituido y constituyente de lo social (Massey, 1994). Nociones como lugar, escala, movilidad o distancia implicaron pensar en construcciones históricas, culturales y políticas relacionadas con la sociedad y el ambiente (Sewell, 2001).

En esa misma línea, los aportes generados por los estudios culturales, colocando al espacio como eje de su análisis, posibilitaron entender los procesos de alta complejidad política, social, económica y cultural que trajo consigo la globalización 
(Marston, 2003). Autores como Castells (1986), analizaron las transformaciones del territorio y del espacio en la ciudad provocadas por el capitalismo y que dieron paso al surgimiento de "movimientos sociales urbanos". En general, desde hace ya algunos años, especialmente dentro de la geografía política y la sociología urbana, y a partir de los cambios provocados por la globalización en el espacio y sus consecuencias para la ciudadanía (Morán, 2005), el espacio y su relación con lo social ha cobrado fuerza.

Ahora bien, en el ámbito de los movimientos sociales el espacio no siempre ha tenido la atención que se merece, en muchos casos ha quedado reducido a un simple escenario estático donde tiene lugar la acción de los movimientos (Marston, 2003; Sewell, 2001). Tratando de ir en otro sentido, recientemente varios autores han contribuido con una serie de reflexiones sobre la importancia del espacio en la actividad de los movimientos sociales. Los aportes de Tilly (2000; 2003), Sewell (2001), Marston (2003) y Martin y Miller (2003), entre otros, han llamado la atención sobre las dimensiones espaciales de la protesta, la influencia del espacio en los repertorios de lucha e identidades dentro de los movimientos, sobre el cambio social y la relación sociedad civil y Estado, el discurso político del espacio público, dinámicas espaciales y control policial, etc. ${ }^{10}$ La mayoría de estos autores forman parten o hacen alusión a uno de los enfoques teóricos más potentes sobre el conflicto social, la denominada "Dinámica de la Contienda Política" (DOC, por el original inglés). Esta propuesta, de McAdam, Tarrow y Tilly (2005) nace con la intención de superar la agenda clásica de los movimientos sociales, considerada por aquellos demasiado estática y centrada en la acción colectiva.

En síntesis, proponen desarrollar un análisis dinámico que logre entender aquellos mecanismos presentes en una variedad de conflictos sociales o de contiendas políticas (Aguilar, 2008a). Entendiendo por contienda política "la interacción episódica, pública y colectiva entre los reivindicadores y sus objetos cuando a) al menos un gobierno es uno de los reivindicadores, de los objetos de las reivindicaciones o es parte en las reivindicaciones, y b) las reivindicaciones, caso de ser satisfechas, afectarían a los intereses de al menos uno de los reivindicados" (McAdam, Tarrow y Tilly, 2005: 5). Distinguen dos tipos de contienda, las "contenidas" y las "transgresivas". Estas últimas incluyen, además de los ítems anteriores, que c) "al menos algunos de los participantes en el conflicto son actores recientemente autoidentificados, y/o d) "al menos algunas de las partes emplean acciones colectivas innovadoras" (McAdam, Tarrow y Tilly, 2005: 8). Y por mecanismos se en-

\footnotetext{
${ }^{10}$ A esta lista de autores se debe agregar otros, que sin adscribirse a la DOC, han realizado valiosos trabajos destacando la importancia del espacio en la actividad de los movimientos sociales. Este es el caso de Javier Auyero (2002), Ulrich Oslender (2002) y Pablo Iglesias (2005). En todos ellos, salvando las distancias de todo tipo, se percibe la necesidad de incorporar al análisis de los movimientos sociales, de la contienda política o de la protesta aspectos espaciales.
} 
tiende "una clase delimitada de acontecimientos que alteran las relaciones entre conjuntos especificados de elementos de maneras idénticas o muy similares en toda una variedad de situaciones" (McAdam, Tarrow y Tilly, 2005: 26) ${ }^{11}$.

\subsection{Un modelo explicativo para entender la relación entre espacio y contienda}

Para Charles Tilly $(2000 ; 2003)$ la relación entre espacio y contienda puede ser explicada por una serie de mecanismos que operan dentro de dimensiones espaciales y que están presentes en la contienda política. Este planteamiento parte del siguiente reconocimiento:

1) Los costos tiempo-distancia y las configuraciones espaciales presentan oportunidades y límites a los participantes en sus reclamaciones públicas; 2) Las distribuciones espaciales, proximidades y rutinas de los participantes potenciales en la contienda afecta la extensión y carácter de la movilización; 3) La acción política interviene en las jurisdicciones espacialmente organizadas de los gobiernos y de este modo incita la intervención gubernamental; 4) Las configuraciones espaciales de la rutina de la vida política dan forma a una contienda no rutinaria; 5) La contienda transforma el significado político de los sitios y las rutinas espaciales (Tilly, 2003: $221)^{12}$.

En síntesis, el espacio influye en la contienda política, en sus protagonistas, sus actuaciones y recursos, de la misma manera en que todas estas actividades contenciosas van resignificando los espacios. Esta idea de espacio tiene mucho en común con lo expresado líneas arriba en cuanto a pensar el espacio como constituido y constituyente de lo social (Massey, 1994). O con las características que Sewell (2001) identifica entre espacio y contienda: "La vida social es situada (...) espacialmente diferenciada", "la localización espacial permite y constriñe la copresencia", "la vida social está organizada dentro de rutinas espaciales"13 (Sewell, 2001:

\footnotetext{
${ }^{11}$ McAdam, Tarrow y Tilly (2005) utilizan la comparación de "casos no comunes" para encontrar aquellos mecanismos presentes en episodios de conflicto y que siendo similares traen consigo consecuencias globales e históricas distintas. Dos de los casos que analizan son la transición española y la guerra civil en Estados Unidos. En ambos casos existen mecanismos causales similares: cambio de identidad, correduría, radicalización y convergencia. Son mecanismos similares que produjeron episodios de contienda diferentes, así mismo, los efectos a gran escala de estos mecanismos dependieron del escenario en el cual operaron, de sus secuencias y combinaciones. El ejemplo del "cambio de identidad" en la sociedad española antes y durante la transición nos da una idea. Dicho cambio operó desde diferentes frentes y aportó a una conciencia europea, secular, mejor formada e informada. En contraste con la polarización de la etapa republicana entre izquierdaderecha. En consecuencia aparecieron identidades orientadas hacia Europa y hacia la autonomía regional. Esto, entre otros mecanismos, puede ayudarnos a explicar aquel episodio.

${ }^{12}$ Traducción propia.

${ }^{13}$ Traducción propia.
} 
56,57 y 62). La "copresencia" 14 de la que habla Sewell está facilitada o constreñida por el tiempo-distancia y por el ambiente construido cultural e históricamente. Visto así, el espacio establece rutinas, incorpora escalas y significados que representan una "matriz de poder" (Sewell, 2001). Tilly engloba todo esto en lo que denomina "sitios sociales" (social sites):

Los sitios sociales consisten en un lugar en el cual la acción humana organizada ocurre: incluyen individuos, aspectos de individuos, organizaciones, redes y lugares. Siempre existen en el espacio, siempre responden a las limitaciones del espacio, lugar y escala, y siempre crean un significado compartido, representaciones que son consecuencia del espacio que ocupan (Tilly, 2003: 222) ${ }^{15}$.

Dentro de los "sitios sociales" Tilly distingue dos dimensiones de variación espacial relevantes: proximidad y movilidad. La primera de las variables "se refiere a los costes de tiempo-distancia de intersección entre sitios sociales, con sus participantes, actividades, objetos, relaciones y representaciones", mientras que la segunda "se refiere a la variación en las conexiones entre grupos de sitios sociales y la superficie de la tierra" (Tilly, 2003: 222). El cruce de las dimensiones produce cuatro tipologías que presentamos tal cual Tilly las expone:

Fija y local: cuando las acciones de reivindicación van unidas a las rutinas, al personal, a las estructuras construidas y geografías simbólicas de los espacios públicos en particular. Fija y de gran escala: la vinculación de las acciones de reivindicación a las representaciones y comunicaciones dentro de los imperios conocidos. Móvil y local: órdenes espaciales altamente transferibles de concentraciones públicas y manifestaciones. Móvil y de gran escala: comunicación y estructuras de coordinación dentro de organizaciones transnacionales (Tilly, 2003: 222) ${ }^{16}$.

Tilly sostiene que entre ambas variables hay diferencias de cara a la contienda política. Las "conexiones de baja proximidad suponen grandes escalas geográficas de coordinación y organización" de la contienda. Las "conexiones fijas de alta proximidad generan conocimiento local importante así como una extensa interacción entre repertorios contenciosos y una rutina de interacción social no contenciosa" (Tilly, 2003: 222). El primero de los casos lo podemos observar en manifestaciones como las "altermundistas" (1999-2003), muchas fueron episodios de contienda organizados a nivel transnacional. El segundo, durante la primera legisla-

\footnotetext{
${ }^{14}$ La idea de "copresencia”, tomada de Giddens (1995), se refiere de manera general a contextos situados de interacción.

${ }^{15}$ Traducción propia.

16 Traducción propia.
} 
tura del PSOE, donde se da un trabajo más grupal y en red que posibilitó reconfigurar repertorios, conocimiento y prácticas en el devenir cotidiano de los colectivos.

La segunda de las variables involucra sensibles diferencias para la contienda. En las "conexiones de gran escala móvil" se "da forma a las distintas manifestaciones de contienda política". En este tipo de conexiones espaciales Tilly coloca lo que Sidney Tarrow (2002) ha llamado "modularidad", es decir, la propiedad que tienen los repertorios de ser compartidos y transferidos a lo largo del tiempo y la distancia. "Las conexiones de gran escala móvil también implican identidades políticas separadas" (Tilly, 2003: pp. 222), es decir, se puede observar en este punto como las identidades políticas, construidas al calor de la contienda, se desplazan entre dos polos: la integración y la separación. En el primero de ellos las relaciones, ideas y representaciones forman parte de la rutina de interacción social y son, en gran parte, la base de las reivindicaciones. Ejemplo de ello son las identidades presentes en el primer sub ciclo: "homosexual", "sin techo", "okupa". En el otro polo tales identidades existen dentro de la contienda, sin embargo, raramente son parte de la interacción social. Como en el caso del segundo sub ciclo, cuando emerge el calificativo de "indignado".

Tilly observa que la "modularidad" de repertorios y la "separación" de las identidades políticas no ocurren juntas, sin embargo, sí se incrementan al aumentar la escala y la movilidad (Figura 1).

Figura 1. Modularización de repertorios y separación de identidades al aumentar escala y movilidad

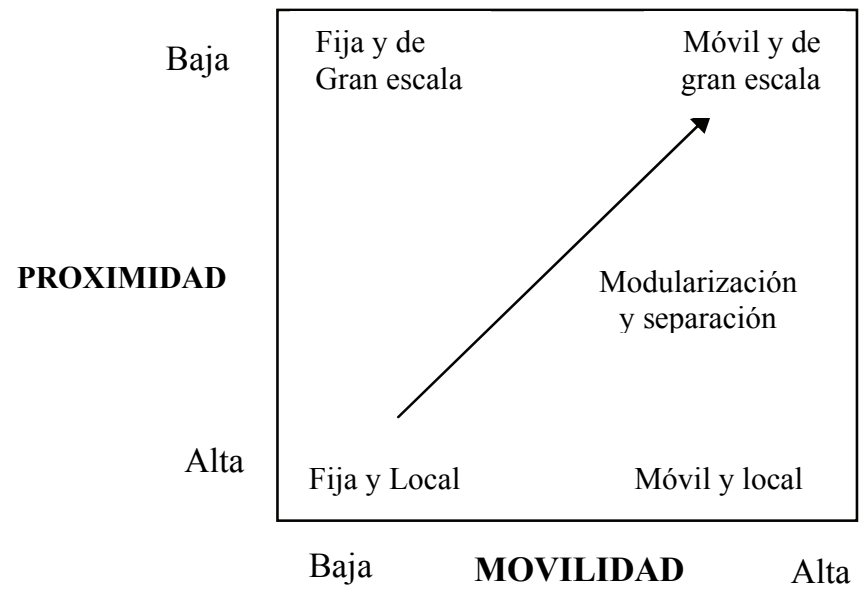

Fuente: Tilly (2003). 
Para entender por qué y cómo ocurre el incremento de la modularidad y la separación al aumentar la escala y la movilidad, Tilly recurre a cuatro mecanismos:

a) Formación de categoría: crea identidades. Ocurre en el "establecimiento de una nueva combinación de reconocida frontera social, relaciones sociales en cada sitio de aquella frontera y relaciones sociales a través de la frontera"; b) Correduría: "la vinculación de dos o más sitios sociales previamente desconectados por una unidad que media sus relaciones uno con el otro y/o con otros sitios"; c) Cambio de objeto: "alteración en las relaciones entre los reivindicadores y los objetos de las reclamaciones"; d) Certificación: "la validación de los actores, sus actuaciones y sus reclamos por las autoridades externas" (Tilly, 2003: 223; McAdam, Tarrow y Tilly, 2005).

Hasta aquí, la teoría propone que estos mecanismos, presentes en la contienda y ligados a categorías espaciales como sitio social, escala, proximidad y movilidad, sirvan para explicar al menos dos fenómenos: la modularidad de los repertorios y la separación de identidades. A esto le agregaremos un tercer elemento, también constitutivo del espacio y relacionado con la contienda política, incluido por Tilly pero poco evidenciado: el significado del espacio (Figura 2).

Figura 2. Proceso de análisis

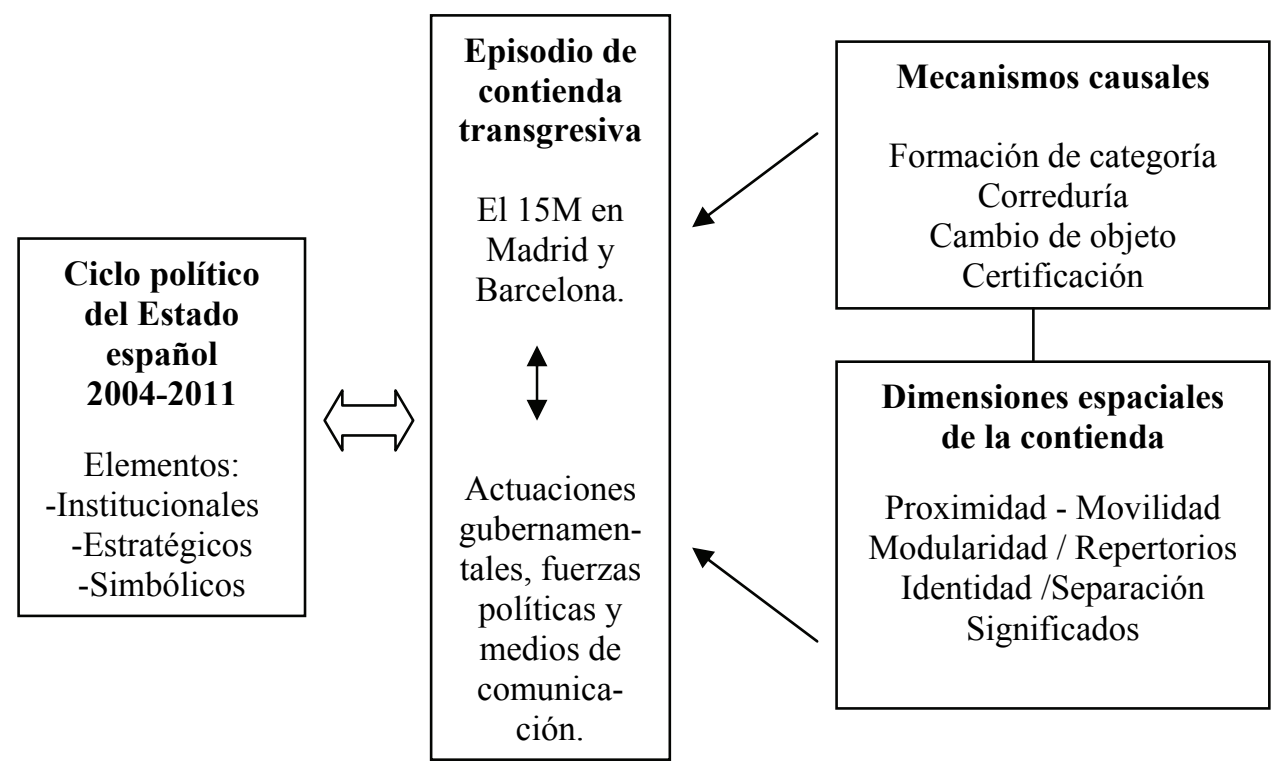

Fuente: elaboración propia 
Desde la geografía no tradicional se ha apostado por una concepción del espacio en todas sus dimensiones, estas incluyen la distancia, la movilidad y el simbolismo. Cada una de ellas contempla dentro de sí significados diversos que dependen del contexto, la cultura o la historia en que son creados, reproducidos y aplicados (Massey, 1984). Para Sewell los espacios incorporan valores simbólicos, "están generizados, racializados y clasificados (gendered, raced, and classed)" (2001: 64). En ese sentido, los significados y valores que los lugares (los "sitios sociales" de Tilly) incorporan son de vital importancia para los movimientos y la contienda política. Según Tilly (2000), el significado político de los espacios tienen una doble importancia, por un lado, al estar disponibles para ser utilizados por aquellos inmersos en la contienda, y por otro, al verse transformados en su contenido político por las acciones contenciosas (2000).

El esquema (Figura 2) sintetiza el proceso de análisis que seguiremos: el "ciclo político" ha sido el antecedente desde el cual hemos partido y desde donde veremos la emergencia del 15-M; en el análisis del episodio rastreamos los rasgos empíricos de la contienda política que dicho movimiento protagonizó y, finalmente, de la relación entre los niveles de mecanismos causales y dimensiones espaciales derivamos la óptica integral de la contienda política específica del movimiento que estudiamos.

\section{El surgimiento del 15-M: identidades, repertorios y simbolismo en disputa}

El día 15 de febrero de 2011 tuvieron lugar una serie de manifestaciones sociales, extendidas por 50 ciudades y dispersas por todo el territorio del estado español. Tales manifestaciones fueron convocadas por la organización "Democracia Real Ya" (DRY) $)^{17}$, organización que en pocos meses había logrado tener bastante presencia dentro las redes sociales. Un activista de Madrid recuerda lo curioso de la convocatoria de DRY: "rebotaba mucho", es decir, tuvo presencia y difusión en las redes sociales (Comunicación personal, 27/07/2012). Sin lugar a dudas las manifestaciones habían sido un éxito: contaron con una gran participación ${ }^{18}$, habían transcurrido sin incidentes y, por contra, exhibieron un ambiente festivo y sin presencia protagónica de partidos ni sindicatos. Tiempo después de terminada esta manifesta-

\footnotetext{
${ }^{17}$ En esta plataforma confluyeron grupos que impulsaron las manifestaciones previas al 15-M, tal es el caso de "Juventud sin futuro" y de colectivos de las nuevas redes sociales que en su momento se opusieron a la "Ley SINDE".

${ }^{18}$ En Madrid la policía calculó 20.000, en Barcelona otras 1.500. El lema de la convocatoria era claro: "No somos mercancía de políticos ni de banqueros". Eran "desempleados, mal remunerados, subcontratados en precario, hipotecados" (El País, 15/05/2012) que habían salido a las calles empujados por la crisis que asolaba España.
} 
ción a nivel del Estado un grupo reducido de activistas (sin vinculación aparente con partidos o con DRY) decide ocupar la Puerta del Sol, ubicada en el centro de la capital española, como forma de continuar la protesta. La respuesta de la policía fue el desalojo violento aunque, en contrapartida, los manifestantes retornaron a la plaza al día siguiente. El 20 de mayo, tan solo 4 días después, se contabilizaban 60 "acampadas" en todo el Estado, una respuesta ciudadana en solidaridad por el desalojo violento ocurrido en Madrid y en protesta por la crisis y las propias demandas locales ${ }^{19}$.

\section{Ilustración 1. Plaça Catalunya ocupada}

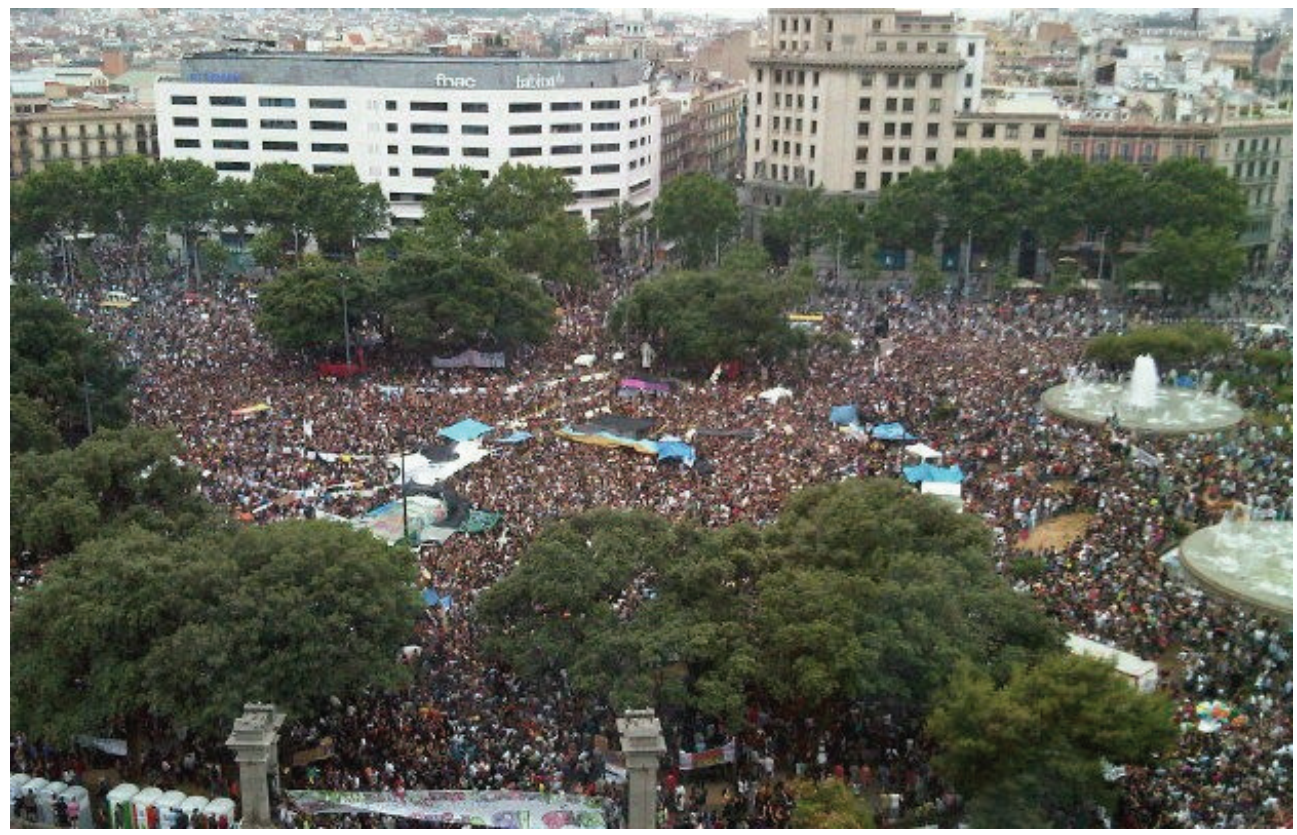

Fuente: URL < acampadabcn.wordpress.com>.

\footnotetext{
${ }^{19}$ Las "acampadas" se refiere a plazas ocupadas al estilo de un campamento, con tiendas de campaña o pequeñas chabolas ("chiringuitos"), desde las cuales se organizó, se construyó y se desplegó el trabajo y la movilización. En el sitio <tomalaplaza.net> se registraban casi 90 en todo el Estado: $<$ http://tomalaplaza.net/lista-de-ciudades-que-ya-han-tomado-la-plaza/ $>$.
} 


\subsection{Breve caracterización del 15-M en Barcelona y Madrid}

Un rápido vistazo de la evolución del 15-M durante sus primeros meses de vida implica, al menos, tres actuaciones: a) una caracterización de sus acciones; b) establecer el tipo de contienda que protagonizó, y c) definir el tipo movimiento que representa.

En la Figura 3 encontramos una síntesis de las acciones más importantes del $15 \mathrm{M}$ entre mayo y junio del 2011, a manera de caracterización cronológica.

Figura 3. Cronología del 15-M

\begin{tabular}{|c|c|}
\hline Barcelona & Madrid \\
\hline $\begin{array}{l}\text {-La primera semana a partir del } 16 \text { de } \\
\text { mayo se constituye en Plaça Catalunya } \\
\text { la acampada Barcelona. } 150 \text { personas } \\
\text { permanecerán esa noche. Primer acuer- } \\
\text { do: tener una asamblea diaria a las } 10: 30 \\
\text { pm. } \\
\text {-Se experimenta una masiva participa- } \\
\text { ción, se organizan comisiones, se } \\
\text { instalan tiendas de campañas y con los } \\
\text { días se monta un campamento alrededor } \\
\text { de la plaza (circular). De ahí que reci- } \\
\text { biera el nombre de "ágora". } \\
\text {-Se coordinan con otras organizaciones } \\
\text { bloqueos a desahucios y acciones contra } \\
\text { los recortes. } \\
\text {-La noche del } 20 \text { se concluye la asam- } \\
\text { blea y se realiza un minuto de silencio, } \\
\text { en seguida aplausos. Así se inicia la } \\
\text { jornada de reflexión previa a las vota- } \\
\text { ciones del } 22 \text {. } \\
\text {-El } 25 \text { de mayo se realiza en conjunto } \\
\text { con otras organizaciones el bloqueo a un } \\
\text { desahucio. Ese día se apoya la manifes- } \\
\text { tación contra los recortes en el Hospital } \\
\text { San Pau (donde todo el personal instaló } \\
\text { su propia "acampada"). } \\
\text {-El } 27 \text { de mayo, los Mossos d' Esquadra } \\
\text { y la Guardia Urbana desalojan violen- } \\
\text { tamente la Plaça Catalunya. Inmediata- } \\
\text { mente una concentración de cientos de } \\
\text { personas rodea de forma pacífica duran- } \\
\text { te varias horas el cordón policial hasta } \\
\text { lograr la liberación de la plaza. - Esa } \\
\text { ana }\end{array}$ & $\begin{array}{l}\text {-Ocupación de una Plaza en Callao, en el } \\
\text { centro de Madrid. Desalojo de la policía y } \\
\text { detención de } 19 \text { personas. } \\
\text {-Ocupación de la Puerta del Sol por un grupo } \\
\text { reducido de manifestantes. Esa misma } \\
\text { madrugada del } 16 \text { de mayo la policía procede } \\
\text { a desalojarlos violentamente. } \\
\text {-El } 17 \text { por la tarde se vuelve a tomar "Sol", la } \\
\text { convocatoria es masiva. } \\
\text {-Durante la semana se crean diferentes } \\
\text { comisiones de trabajo, las cuales sufren } \\
\text { cambios a lo largo del mes de ocupación. } \\
\text { Surge bajo carpas y mantas una pequeña } \\
\text { ciudad. } \\
\text {-Muestras de solidaridad en otros países, } \\
\text { algunos de ellos ocupan momentáneamente } \\
\text { embajadas y consulados de España. } \\
\text {-Los partidos políticos se pronuncian (en } \\
\text { todo el Estado) haciendo suyas las demandas } \\
\text { de los indignados. } \\
\text {-El } 19 \text { de mayo la Junta Electoral Provincial } \\
\text { declara ilegales las concentraciones durante } \\
\text { la jornada de reflexión y las votaciones ( } 21 \text { y } \\
\text { 22 de mayo respectivamente). El } 15-M \text { sigue } \\
\text { en la Puerta del Sol, convoca a los ciudada- } \\
\text { nos a manifestarse en las urnas colocadas en } \\
\text { la plaza y con ello hacer sus propuestas. } \\
\text {-El } 21 \text {, día de reflexión, } 28.000 \text { personas } \\
\text { (según la policía) se dan cita en Sol. Se } \\
\text { produce "el grito de silencio". } \\
\text {-Emergen conflictos por el supuesto descenso } \\
\text { en las ventas con la Confederación de Co- } \\
\text { mercio Especializado de la Comunidad de }\end{array}$ \\
\hline
\end{tabular}




\begin{tabular}{|c|c|}
\hline $\begin{array}{l}\text { de mayo, el F.C. Barcelona gana } \\
\text { hampions" (torneo europeo de } \\
\text { y los hinchas celebran en la } \\
\text { la de Canaletas (muy cerca de la } \\
\text { Los indignados aíslan y resguar- } \\
\text { plaza y con ello evitan que la } \\
\text { a lo use de pretexto para desalojar- } \\
\text { de mayo, concentración en el } \\
\text { lado francés en apoyo al desalojo } \\
\text {-M Paris. } \\
\text { mayo, manifestación masiva en } \\
\text { lona contra el desalojo de la Plaça } \\
\text { inya. } \\
\text { nte la primera semana de junio el } \\
\text { apoyará la concentración en las } \\
\text { as de la SEAT, YAMAHA, } \\
\text { nnica, del Hospital Vall d' Hebron, } \\
\text { estación a los indignados de } \\
\text { cia. } \\
\text { de junio se lleva a cabo un encuen- } \\
\text { asambleas de barrios y pueblos de } \\
\text { ña en la Plaza. } \\
\text { de junio la asamblea decide } \\
\text { onar la plaza durante la semana. } \\
\text { de junio, y producto de un acuer- } \\
\text { todas las acampadas, hay una } \\
\text { ntración, "sentadas" y diferentes } \\
\text { en los Ayuntamientos de munici- } \\
\text { ciudades aprovechando la toma } \\
\text { sesión de los nuevos responsables. } \\
\text { nte esa semana se deja la Plaça } \\
\text { inya. Se mantienen actividades } \\
\text { te el día y un puesto de informa- } \\
\text { rupo de "indignados" autodenomi- } \\
\text { "ágora" se mantienen en la plaza. }\end{array}$ & $\begin{array}{l}\text { Madrid (COCEM) (Reclaman al Ministerio } \\
\text { del Interior } 30 \text { millones en pérdidas debido a } \\
\text { la acampada). } \\
\text {-27 de mayo, en Sol se convoca a una con- } \\
\text { centración en apoyo a los indignados de } \\
\text { Plaça Catalunya desalojados por la mañana. } \\
\text {-Al final de la segunda semana el movimien- } \\
\text { to se empieza a articular en los barrios, se } \\
\text { celebran las primeras asambleas locales. } \\
\text {-El gobierno regional y del ayuntamiento de } \\
\text { Madrid solicita el desalojo aduciendo peli- } \\
\text { gros de salud pública y efectos en el comer- } \\
\text { cio de la zona. El movimiento decide perma- } \\
\text { necer de manera indefinida y se plantean la } \\
\text { restructuración del campamento. } \\
\text {-A principios de junio se producen encuen- } \\
\text { tros a nivel del Estado para analizar la evolu- } \\
\text { ción del movimiento y plantear nuevas } \\
\text { acciones. Se propone una marcha nacional la } \\
\text { cual: "tomar Madrid" y "refundar la demo- } \\
\text { cracia". } \\
\text {-El } 8 \text { de junio se produce una "sentada" del } \\
\text { movimiento indignado en el Congrego de los } \\
\text { Diputados contra la reforma laboral. Deciden } \\
\text { no acampar en ese sitio y regresar a Sol. Al } \\
\text { día siguiente se produce otra "sentada" en el } \\
\text { Congreso de los Diputados a fin de solidari- } \\
\text { zarse con los indignados de Valencia que } \\
\text { durante la mañana habían sido reprimidos por } \\
\text { la policía. } \\
\text {-10 de junio, luego de las acciones e inter- } \\
\text { vención de la policía en Barcelona y Valen- } \\
\text { cia, el Ministro del Interior advierte: "la } \\
\text { policía actuará con firmeza si hay violencia". } \\
\text {-El } 11 \text { de junio, y producto de un acuerdo de } \\
\text { todas las acampadas, hay una concentración, } \\
\text { sentadas y diferentes actos en los Ayunta- } \\
\text { mientos de municipios y ciudades aprove- } \\
\text { chando la toma de posesión de los nuevos } \\
\text { responsables. } \\
\text {-12 de junio, luego de cuatro semanas, los } \\
\text { indignados de Sol levantan el campamento. } \\
\text { "No nos vamos, nos expandimos". }\end{array}$ \\
\hline
\end{tabular}

Fuente: elaboración propia a partir de periódicos españoles y catalanes y páginas del movimiento 15-M. 
La actividad del 15-M durante el mes de ocupación de las plazas se caracterizó de manera general, tanto en Madrid como en Barcelona, por momentos de intensidad máxima durante las primeras dos semanas seguidos por un cierto decaimiento hacia la tercera y parte de la cuarta semanas. Era de esperar que el cansancio y el desgaste de todo tipo cobraran factura. Durante aquel último periodo se observó un mayor cuestionamiento del hecho de mantener las plazas ocupadas y además un descenso en la participación dentro de las comisiones. Ahora bien, el punto de inflexión que marcó el declive es distinto para ambos casos. En Madrid lo constituyó la jornada de reflexión del día 21 de mayo, durante la cual la posibilidad del desalojo se hizo presente al tiempo que se vivía un "acto masivo de desobediencia civil" (Pastor, 2012). En Barcelona tal punto lo marcó el desalojo del día 27 de mayo, a partir del cual las tensiones dentro de la plaza serían menos llevaderas y la posibilidad de dejarla empezó a cobrar fuerza. Ambos puntos de inflexión, y en ambos casos, por un lado, darían un empujón final a la idea del trabajo barrial, por otro, coincidirían en el tiempo con la emergencia de tensiones y un cambio en la opinión pública sobre la imagen de las plazas ${ }^{20}$.

El tiempo de ocupación, y el que prosiguió unos meses después, adquirió características indudables de una "contienda política transgresiva" (McAdam, Tarrow y Tilly, 2005: 17). La interacción "episódica, pública y colectiva" fue protagonizada por el 15-M, un reivindicador "recientemente autoidentificado" que encontró en las autoridades, partidos y políticos (y sus fuerzas policiales) el objeto de sus reivindicaciones. Los momentos de mayor tensión para ambos estuvieron presentes durante los desalojos, la jornada de reflexión y en el asedio que el 15-M mantuvo sobre el Congreso de los Diputados en Madrid y el Parlament en Cataluña. Sus reivindicaciones, en muchos casos de gran amplitud y poca precisión ${ }^{21}$, de haberse cumplido implicaban cambios que afectaban los intereses del gobierno y la clase política. Sin embargo, una reivindicación que se hacía efectiva durante la contienda y que supuso la mayor tensión fue la ocupación del espacio público como derecho ciudadano. Finalmente, las acciones impulsadas, algunas "innovadoras", no inéditas claro está, se centraron especialmente en el uso del internet (y sus distintas herramientas y

\footnotetext{
${ }^{20}$ Las tensiones fueron varias, algunas de convivencia dentro de las plazas, otras, sobre un debate, supuestamente resuelto, aunque no del todo o para todos, sobre formas de lucha de mayor contundencia, lo cual en cierta medida cuestionaba el pacifismo o la acción directa no violenta ante la represión policial. Por otra parte, la aceptación social, y sobre todo, la imagen que empezaron a trasladar los medios masivos de comunicación sobre el 15-M y las ocupaciones irían cambiando en ambos casos.

${ }^{21} \mathrm{La}$ ardua tarea de sistematización hecha por el $15-\mathrm{M}$ posibilita seguir el rastro de este argumento. Para Madrid ver "cuatro líneas de debate" [URL <http://madrid.tomalaplaza.net/2011/05/26/acampada-solconsensua-cuatro-lineas-de-debate/>. En Barcelona ver "demandes mínims" [URL: $<$ http://acampadadebarcelona.org/es/acampadabcn/documents/demandes-de-minims/item/123-demandes-de$\mathrm{m} \% \mathrm{C} 3 \% \mathrm{ADnims}>$.
} 
plataformas) y la ocupación del espacio público en forma de "acampada" (tipo campamento o pequeña ciudad).

\section{Ilustración 2. Puerta del Sol ocupada}

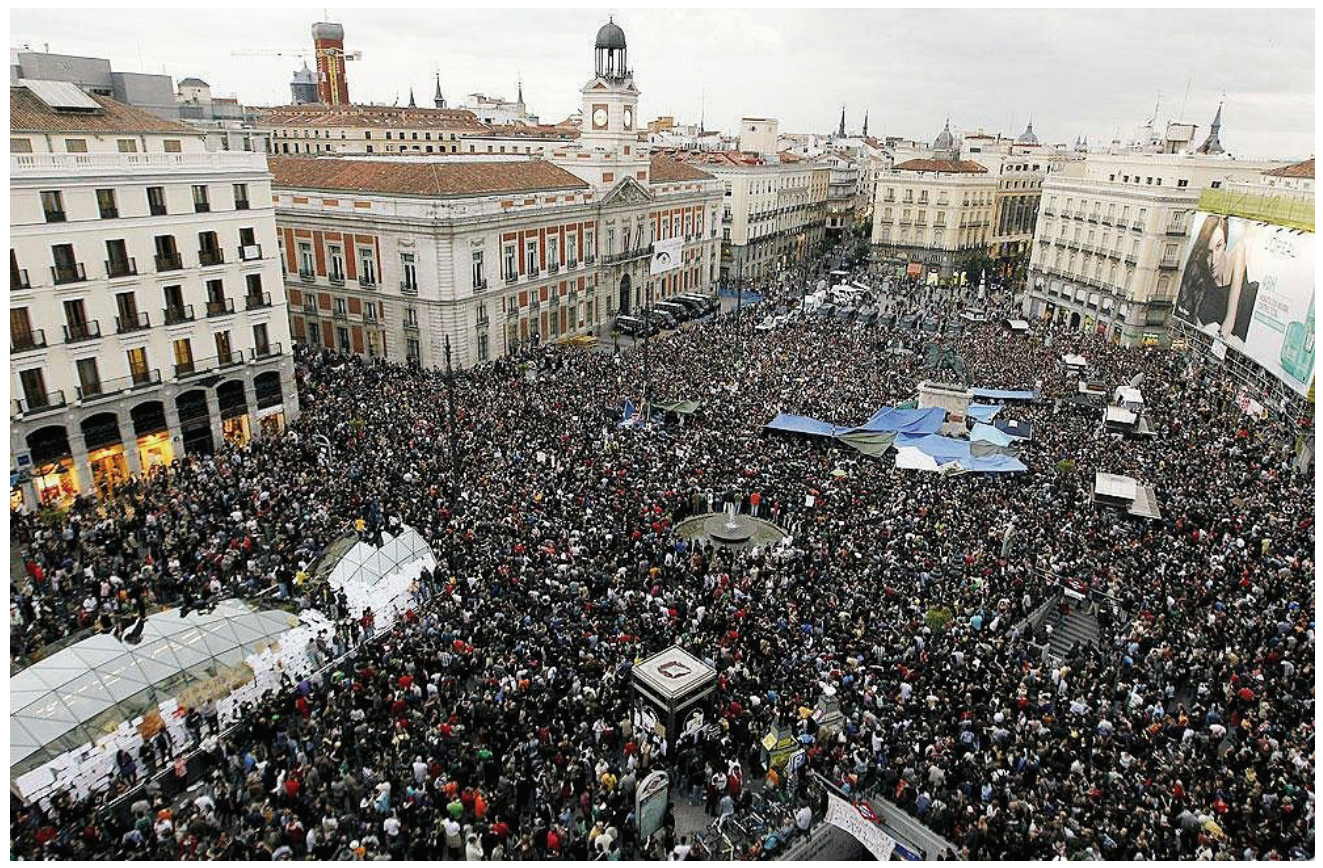

Fuente: URL < tomalaplaza.net $>$.

El 15-M forma parte de aquellos movimientos ciudadanos que nacen espontáneamente, en este caso como expresión probable de la indignación de la situación de crisis, sin embargo, reconocen y expresan rápidamente otros reclamos ligados al sistema político, social y económico. Si bien ha sido sumamente diverso, ahí su fortaleza y gran complejidad, lo une la indignación y la expresión de ciertos valores. ${ }^{22} \mathrm{Se}$ organiza de manera horizontal, sin liderazgo centralizado, mantienen un rechazo a la política institucional pero es decididamente político (Castells, 2012).

\footnotetext{
${ }^{22}$ Durante las primeras dos semanas, en medio de un relacionamiento intenso, existió algo acuñado por un activista como "el espíritu de la plaza" (activista de Barcelona, comunicación personal, 06/07/2012), entendido como respeto, apoyo mutuo, solidaridad. Estos valores, junto al pacifismo y la democracia como práctica cotidiana, atravesaron el modelo organizativo basado en grupos de trabajo, comisiones y asambleas.
} 
Sus formas de lucha están influidas por el pacifismo, la acción directa y no violenta. En su discurso y acción "parece combinar trazos no desdeñables de anti-política (...) una determinación por acabar con las formas inaceptables que se han instalado en las infrademocracias occidentales" (Aguilar et al., 2012: 171-172)23.

\subsection{Potenciación de redes y nuevas identidades}

Las personas que iniciaron las ocupaciones de las plazas en Madrid y Barcelona entre el 16 y 17 de mayo no superaban las 100 en cada caso, pocos días después eran miles las que asistían a las asambleas y manifestaciones que se convocaban desde estos $\operatorname{sitios}^{24}$. La masificación acelerada se debió a muchos factores (la represión policial inicial, la generalidad de sus propuestas que sumaron gente, el pacifismo, el momento de indignación), sin embargo, la difusión y las nuevas tecnologías como formas de lucha fueron un propulsor inimaginable. El 15-M que tomó cuerpo en las plazas contaba ya con una sociedad en red, conectada por múltiples formas (Facebook, Twitter, etc.), esto le ayudó desde el inicio a masificar sus convocatorias. Así, se convirtió en ese tipo de movimientos que utilizan "comunicación multimodal" y son altamente "expansivos" (Castells, 2012).

El 15-M se expandió por el Estado, y las acampadas por el mundo ${ }^{25}$. La plaza, situada en un escala de "alta proximidad", es decir, donde los costes tiempodistancia entre sitios son mínimos, se convirtió en un "sitio social" de gran relacionamiento, de flujo de información, de comisiones funcionando como "celdas" (Comunicación personal activista de Madrid, 26/09/2012), las cuales socializaban su trabajo en las asambleas, el órgano decisorio. El excesivo debate retroalimentaba, pero no pocas veces provocó el desgaste. En medio de este auge, la idea de conectarse hacia los barrios, ampliando la escala y la movilidad, surge en ambos lugares. En Madrid, el 28 de mayo se realizan alrededor de 100 asambleas barriales y tiempo después se crearía la Asamblea de Pueblos de Madrid (APM).

\footnotetext{
${ }^{23}$ Las reivindicaciones asumidas desde un inicio fueron de carácter general, lo cual fue un buen punto de enganche para sumar gente. Tanto en Madrid como en Barcelona estuvieron relacionadas con esa crítica a las "infrademocracias occidentales", aunque con las comisiones en funcionamiento la lista de peticiones se ampliaría grandemente e incluiría casi cualquier preocupación.

${ }^{24}$ En Madrid la noche del 20 de mayo, previo a la jornada de reflexión acostumbrada antes de cualquier evento electoral, se llegaron a reunir 22.000 personas (El País, 21/05/2012). Luego del desalojo de Plaça Catalunya el 27 de mayo, esa misma noche se concentraron alrededor de 12.000 personas según la policía (El Mundo, 31/05/2011).

${ }^{25}$ En este enlace se puede observar su distribución geográfica en el Estado español: URL $<$ http://www.lavanguardia.com/politica/20110519/54156763904/los-acampados-resisten-una-nueva-nochedesafiando-la-prohibicion-de-la-junta-electoral.html>. En este otro su alcance planetario: URL $<$ http://www.ikimap.com/node/8702/fullmap $>$.
} 
En Barcelona, con un gran historial organizativo barrial, se inicia la conformación de las asambleas antes del desalojo del 27 de mayo, uno de los activistas recuerda que "no había directriz desde la plaza, fue auto organizado" (Comunicación personal, 19/07/2012). De tal cuenta, se conformaron asambleas en barrios como Les Corts y Sarriá, y, asimismo, se fortaleció el trabajo en barrios con una tradición organizativa más fuerte, y anterior al 15-M, como Gracia, Poble Sec y Sants. En este último barrio existió una acampada durante dos semanas, tenía dinámicas, "a muy pequeña escala", similares a la ubicada en la Plaça Catalunya. Había gente de distintos colectivos: centros sociales (CanVies), Castellers, Asamblea de Barrio, movimiento libertario, etc. (Comunicación personal activistas de Barcelona, 11/09/2012, 19/07/2012).

No cabe duda de que las nuevas tecnologías facilitaron esta expansión, sin embargo, para hacer uso de esta facilidad tecnológica primero existió la voluntad de conectarse y la necesidad de articular la movilización social. El mecanismo de "correduría" se encuentra presente cuando observaros que ocurre "la vinculación de dos o más sitios sociales desconectados". En Madrid como en Barcelona, el 15-M, entre otros factores, ayudó a vincular esos actores y voluntades. Así, la "baja proximidad", aumentando los costes tiempo-distancia entre los sitios sociales, y una "alta movilidad", haciendo variar las conexiones entre las plazas y los puntos fijos y locales, sería tendencia a seguir y la correduría lo que lo haría posible. Los activistas en Barcelona y Madrid, en especial los involucrados en acciones de comunicación, reconocen el papel de "puente" que el 15-M jugo a nivel estatal conectando las asambleas, enlazando colectivos no vinculados y a nivel internacional difundiendo los acontecimientos y contribuyendo a la formación de un movimiento internacional que se expresó en plataformas como "takethesquare", o bien, en el nacimiento, posterior a la plaza, del colectivo "Auditoría de la Deuda", un grupo que al día de hoy se articula a nivel europeo (Comunicación personal activista de Barcelona, 07/07/2012). En general, el 15-M es un movimiento funcionando en una lógica de "código abierto", organizado desde abajo se retroalimenta y se expande (Comunicación personal activista de Madrid, 26/09/2012).

Otra cuestión, relacionada con lo anterior, tiene que ver con la identidad del 15M. Mucho de lo que se ha escrito sobre este movimiento (Andreu, 2012; Calle, 2011; Castells, 2011a, 2011b, 2012; CIS, 2012; De la Rubia et al., 2011; Ezquerra, 2011, 2012; Fernández, 2011; García-Rosales y Penella, 2011; Giner, 2012; Martí i Puig, 2011; Mora, 2011; Pastor, 2012; Taibo, 2011a, 2011b; Viejo Viñas, 2011) destaca su diversidad (en ideas, valores, experiencias, etc.), que señala como una de sus fortalezas ${ }^{26}$. Tanto en Madrid como en Barcelona los activistas reconocen el

\footnotetext{
${ }^{26}$ La mayor parte de los activistas del 15-M, en especial durante las primeras semanas, eran jóvenes, muchos de ellos estudiantes universitarios y no organizados hasta aquel momento, posiblemente para muchos el 15-
} 
respeto ante tal variedad de experiencias. Esta situación explica porque algunos activistas del 15-M asumieron la plaza como un espacio "sin banderas" (Comunicación personal activista de Barcelona, 06/07/2011). En otros casos, y ante la insistencia que políticos y medios de comunicación tenían por identificarlos, un activista recuerda uno de los carteles que permaneció por mucho tiempo en Sol: "no somos de izquierda ni de derecha, somos los de abajo que vamos por los de arriba" (Comunicación personal activista de Madrid, 26/07/2012). También lo explica largos años de desencanto con la política institucional, de ahí el distanciamiento del movimiento con las identidades y las lógicas vinculadas a partidos políticos y sindicatos, aunque "asumían consignas - luchas - características de la izquierda" (Comunicación personal activista de Barcelona, 19/07/2012). Incluso las identidades independentistas perdieron terreno en Cataluña, al menos en un inicio, aunque tiempo después se aceptó dentro de "los mínimos" la demanda de autodeterminación, sin embargo, este tema nunca fue un eje importante en la lucha del 15- $\mathrm{M}^{27}$. En general, el movimiento se veía así mismo conectado más con los problemas nacionales y globales que locales.

Para Tilly (2003) las identidades presentes en la contienda política pueden llegar a transformarse en la medida en que o en tanto que se produce una variación en las variables espaciales. Específicamente, afirma que se produce una "separación" de las identidades al momento de ampliarse la escala e incrementarse la movilidad, es decir, en la medida en que el 15-M se fue expandiendo territorialmente, y con ello haciendo variar exponencialmente sus conexiones entre "sitios sociales", las identidades y las reivindicaciones que se expresaron asumieron un carácter más global. Así, "indignado" o "Spanish revolution" adquiere un carácter integrador de múltiples luchas, a la vez que se asume una órbita de gran escala. Un activista de Barcelona aseguraba que "el espacio de la plaza estaba por encima. No había espacio para una reivindicación sectorial. Se trataba del mundo, no de Cataluña" (Comunicación personal activista de Barcelona, 06/07/2012). También es cierto, como bien lo señala uno de los activistas, que las denominaciones de "indignado" y la de "15-M"

M representaba su primera experiencia en el activismo político. Otro grupo, más reducido, lo conformaban activistas que provenían del movimiento okupa, centros sociales, universidad, etc., con un activismo que se remontaba a las luchas contra la guerra en Irak (del tipo altermundista), las luchas por la vivienda digna (V de Vivienda y después la PAH), y más recientemente las movilizaciones contra el "plan Bolonia", etc.

${ }^{27}$ La mayoría de los entrevistados coincidió en que la rivalidad Madrid-Barcelona no había tenido lugar, aludiendo a que no se había caído en el juego de la confrontación. En Barcelona se recuerda la solidaridad de Madrid ante el desalojo (Comunicación personal activistas de Barcelona, 06/07/2012; 07/07/2012; 19/07/2012). La gente de Madrid recuerda que durante el desalojo de la Plaça Catalunya "se lanzaron hashtag en catalá" y se realizó una manifestación masiva de denuncia y solidaridad (Comunicación personal activista de Madrid, 13/07/2012). Aquellos con un sentimiento más independentista asumen que dicha rivalidad quedó en segundo plano, sin embargo, no así la demanda independentista y su crítica con respecto al Estado español. 
surgen ante la necesidad de los medios de comunicación de nombrar un movimiento "escurridizo totalmente a las etiquetas y a la identificación" (Comunicación personal activista de Madrid, 13/07/2012). En ese sentido, la contienda política también se libró en el plano simbólico y en el de la identidad.

\subsection{Creación, resignificación y difusión de repertorios}

El 15-M utilizó infinidad de formas de lucha para sacar adelante sus reivindicaciones. Las manifestaciones desde las plazas hacia el Congreso de los diputados en Madrid o hacia el Parlament en Cataluña, o bien las caceroladas organizadas en Barcelona durante varios días justo antes de iniciar las asambleas, podrían entenderse como las más tradicionales. A éstas se suman acciones lúdicas, de denuncia, simbólicas y transgresivas ${ }^{28}$. En estos casos el espacio limitó o facilitó la movilización y configuró la dinámica con las fuerzas públicas ${ }^{29}$. Aunque en esto último hubo matices. En Madrid la policía actuó con más tolerancia luego de los dos desalojos iniciales, contrario a lo que sucedía en Barcelona, donde la confrontación con la policía era algo siempre latente. Los hechos ocurridos en el Parlament catalán el 15 de junio, además de un punto importante de inflexión para el 15-M, evidenciaron el recrudecimiento de la represión y confirmaron la vocación no violenta del movimiento.

Por otro lado, algo distintivo en las formas de lucha del 15-M fue el uso de internet. Una cuestión característica en aquellos movimientos que asumen las "nuevas formas de organización y movilización social representativas de la cultura y la tecnología de nuestro tiempo" (Castells, 2012: 12). El internet les permitió "acciones innovadoras" (McAdam, Tarrow y Tilly, 2005) a través de una "comunicación multimodal" y presentarse con un carácter "expansivo". Otra importante característica en ese sentido fue el énfasis en la ocupación del espacio público (Castells, 2012; Aguilar et al., 2012).

\footnotetext{
${ }^{28}$ Un ejemplo son las "batucadas" o las acciones de "flashmob", la recogida de firmas dentro de las plazas sobre algún tema, la ocupación del metro, de bancos, etc. También existieron comisiones encargadas de la acción directa. En muchos casos ésta realizó acciones en las cercanías de las plazas o las coordinó con otros colectivos.

${ }^{29}$ Durante las manifestaciones la dinámica de la contienda incluía espacios de concentración, recorridos, sitios emblemáticos, confrontación o tensiones con la policía. En Barcelona la situación de la plaza proveía de mucha visibilidad, a está llegaban calles como Vía Laietana que se convirtió en un conducto amplio hacia la zona cercana al Parlament, recorrido bastante habitual. En el caso de Madrid la cuestión no era tan sencilla dado que "Sol" está en un enclave en el cual desembocan 10 calles. Ambas plazas están situadas en zonas de gran comercio y, por ello, con mucho tránsito.
} 
La ocupación y el asamblearismo como forma de protesta tienen una larga historia dentro de los movimientos sociales ${ }^{30}$. Ahora bien, la ocupación de una plaza (un espacio público, cargado de simbolismo en muchas ciudades) en combinación con el asamblearismo fuera de las paredes de Congresos y Parlamentos, sí que puede ser un aporte innovador a una práctica ya conocida ${ }^{31}$. Así, "el espacio ocupado se convierte en comunidad y en experimento de democracia y vida alternativas, buscando formas que prefiguren una futura democracia real viviéndola en la práctica" (Castells, 2012: 15). También se convierte, tal como lo expresan los activistas, en "herramienta de visibilización", en "un espacio público para deshabilitar un problema y para organizarnos y defendernos" (Comunicación personal activistas de Madrid, 11/07/2012 y 27/07/2012). Aunque claro, para otros no era suficiente: "No estabas colapsando las vías de comunicación importantes en Barcelona, el sistema productivo, más allá de organizarse no había ninguna amenaza" (Comunicación personal activista de Barcelona, 19/07/2012).

Otras acciones combinan perfectamente el espacio, los valores y formas simbólicas de acción, logrando con ello contundencia y una onda expansiva. Un ejemplo de esto fue "el grito mudo" realizado coordinadamente el 20 de mayo en todas las acampadas del Estado (Comunicación personal activista de Madrid, 27/07/2012) ${ }^{32}$. La "marcha popular indignada", organizada y realizada semanas después de dejar las plazas, también podría considerarse en este sentido ${ }^{33}$. En estos ejemplos subyace

\footnotetext{
${ }^{30}$ Tilly (2002) observó muy bien cómo las reuniones y asambleas habían logrado convertirse en "repertorios" de lucha en Inglaterra a lo largo de casi cien años. Había sucedido un tránsito de los actos directos y violentos a acciones más del tipo parlamentarista. Hacia 1830, las asambleas eran consideradas de uso normal y, por tanto, aceptadas como práctica política.

${ }^{31}$ En Europa un referente de este tipo de acción es el movimiento "Reclaim the streets" creado por Earth first en Londres en 1991. En el Estado español, dejando de lado el movimiento "okupa" o "los encierros", la ocupación del espacio público como forma de protesta tiene varios precedentes: la "Plataforma $0,7 \%$ " que luchaba por el 7\% del PIB destinado a cooperación en 1994, el campamento asentado durante medio año en el Paseo de la Castellana por los trabajadores de SINTEL en protesta por despidos masivos en 2001, y las "sentadas" en las plazas a nivel nacional del movimiento "V de vivienda" en el 2006.

${ }^{32}$ Pocos días antes de la realización de las elecciones municipales del 22 de mayo en todo el Estado, la Junta Electoral Provincial, con sede en Madrid, había declarado ilegales las concentraciones en las plazas. No deseaban que existiera ningún tipo de propaganda política durante la jornada de reflexión tradicionalmente hecha un día antes del evento electoral. Con lo cual el desalojo se hacía inminente. Aquella noche en Sol 28.000 personas abarrotaron la plaza (El Pais, 22/05/2011), existió tensión y mucha convicción. Los activistas de Madrid lo recuerdan como "el minuto de silencio" o "el grito mudo": "La gente se coloca esparadrapo en la boca. A las 12 PM un minuto de silencio y manos al aire, luego se quitaron el esparadrapo y un grito colectivo" (Comunicación personal activistas de Madrid, 11/07/2012, 26/07/2012 y 27/07/2012). En Barcelona, según los periódicos, se dieron cita esa noche 5.000 personas.

${ }^{33}$ La marcha, una idea nacida en Barcelona, fue una acción planificad a nivel estatal, unas semanas antes, en el encuentro que tuvo lugar en Madrid entre varios portavoces de las distintas "acampadas". Se acordaron que cinco columnas saldrían de 9 ciudades distintas, a su paso realizarían "acampadas", asambleas y recogerían las propuestas de todas las localidades que visitaran. La marcha de Barcelona salió el 25 de junio con 100 personas. Todas las columnas hicieron contactos previos, coordinaron la alimentación y demás
} 
la idea de "modularidad" a la que Tilly hacía referencia, es decir, la posibilidad o potencial que tiene un repertorio de lucha para convertirse en modelo, que pueda ser transferible y verse compartido por otros grupos y en otros lugares. Ahora bien, solo cuando la "movilidad" es alta y la "proximidad" es baja — del tipo "móvil y de gran escala" (large scale mobile) - se hará más evidente que un repertorio ha pasado a ser compartido. De toda la experiencia del 15-M esto ha sucedido con la idea de "acampar", en especial ligada a la posibilidad de hacerlo en una plaza pública.

\subsection{Re-significación política del espacio y la actividad contenciosa}

Tilly $(2000$; 2003) sostiene que la contienda política transforma los significados políticos de los espacios. Antes del 15-M la Puerta del Sol y la Plaça Catalunya no tenían otro significado que la de ser punto de encuentro, uno de los tantos espacios emergidos de las sucesivas transformaciones urbanas, sin otro fin que la de facilitar cualquier tipo de exposición comercial y consumo. Con la actividad del 15-M ambas plazas adquirieron - de modo efímero, si se quiere- un nuevo significado. Especialmente en sus primeras semanas, se convirtieron en un lugar de solidaridad, de expresión de la indignación, en un espacio seguro. Era vista por los activistas como una herramienta de protesta, pero a la vez, como lugar de aprendizaje. Con el tiempo, y debido a las tensiones internas y la presión del posible desalojo, también se percibió como "un peso grande" (Comunicación personal activista de Madrid, 13/07/2012).

La intensidad inicial de las acampadas no permitió descifrar cómo se habían edificado. La dinámica espacial estuvo marcada por una gran dosis de espontaneidad, en consecuencia la distribución del espacio entre comisiones respondió a sus necesidades cotidianas. La configuración que fue adquiriendo cada plaza, además de única, propició un relacionamiento estrecho y se acopló al modelo organizativo. Con el tiempo ciertos sitos dentro de las plazas cobraron relevancia: "el Caballo" en Madrid fue lugar inicial de asambleas, en seguida suplido por "la ballena", frente a la salida del metro. En Cataluña, gracias a su forma circular, se tuvo más fácil en cuanto a la realización de asambleas. Ahora bien, en ambos casos la plaza fue insuficiente, de ahí que fuera necesario ocupar otros espacios cercanos ${ }^{34}$.

servicios. Las cinco columnas entraron coordinadamente a Madrid y llegaron a Puerta de Sol donde fueron recibidas por 20.000 personas, en una actividad masiva y emocionante. Ese mismo día fueron a acampar al Paseo del Prado. El denominado "documento de los pueblos" (10 páginas plagadas de peticiones recogidas en los recorridos) se llevó al Congreso de los Diputados, no sin antes sortear a la policía y encontrar un aliado de un partido de izquierda que introdujo el documento a debate.

${ }^{34}$ En muchos casos se hizo necesario ocupar otros espacios cercanos a las plazas. En Barcelona se ocupó "la placita de las palomas" o la puerta del banco BBVA (Comunicación personal activista de Barcelona, 06/07/2012), en Madrid las diferentes plazas que hay cerca de la Puerta del Sol conformaban ya parte del "territorio del 15-M" (Comunicación personal activistas de Madrid, 27/07/2012). 
Otra cuestión importante relacionada con la anterior, es el papel que juegan los espacios en la configuración de la contienda y de la memoria de los movimientos. Una de las personas entrevistadas recuerda la noche del 17 de mayo en Plaza del Sol como un acto de solidaridad por el desalojo: las "redes sociales estaban hirviendo" ante la convocatoria, "estábamos cargados de lo que había pasado el 15, la gente como que no quería irse, como diciendo bueno y ahora qué (...) Esa chispa sirvió" (Comunicación personal activista de Madrid, 27/07/2012). La necesidad de continuar era un sentimiento provocado por la misma manifestación, las cuales desde hacía algún tiempo se habían convertido en un "eufemismo" de principio a fin (Morán, 2003). De pronto lo espontáneo, lo autoorganizado surgió: "alguien invitó a hacer un círculo en el caballo", se tiraron cordones, plásticos y se colocaron cartones en el suelo, se delineó lo que pronto sería una pequeña ciudad (Comunicación personal activista de Madrid, 11/07/2012).

En la medida en que en las plazas se fue sumando gente aparecieron distintos problemas en cuanto a mantener el espacio limpio y con cierto funcionamiento. No beber en las plazas pasó de ser una norma de "sentido común" a hacerse explicita, se intentaba evitar cualquier situación que justificara el desalojo. En ambas plazas la responsabilidad de la convivencia era del $15-\mathrm{M}^{35}$, de ahí que surgiera en cada una de ellas una "comisión de respeto" encargada de velar por el buen relacionamiento. Algo de suma importancia al momento de convivir con aquellas personas (indigentes) que ya vivían en las plazas o muy cerca de ellas. A pesar de todos estos esfuerzos, y en especial tras las elecciones municipales, la prensa, sobre todo la conservadora, empezó a generar un desgaste sostenido sobre las ocupaciones de las plazas. Acunó el término de "perroflautas" para referirse despectivamente a la mayoría de los activistas del 15-M, o bien, a "estigmatizar y criminalizar ciertos espacios de la plaza" asegurando que existían "tiendas del amor" o "macrofiestas" durante las noches. Según un activista de Barcelona, "la plaza ganó simpatía y rechazo" (Comunicación personal activista de Barcelona, 06/07/2012).

Las plazas convertidas en "sitios sociales" tienen en sí muchas historias y sentidos, en especial para quienes construyeron ahí "un mundo mejor". Todos los entrevistados, con metáforas diferentes, recuerdan "Sol" o Plaça Catalunya como "un mundo aparte", como una especie de "burbuja" (Comunicación personal activistas de Barcelona, 06/07/2012). Sin embargo, y aunque Plaça Catalunya está más aislada del paso de la gente que Sol, en ambos casos "salir de la plaza era un shok, te dabas cuenta que no todos pensaban como tú" (Comunicación personal activista de Madrid, 27/07/2012). Otro aspecto importante de aquel "espíritu de la plaza" fue su estética. Es decir, la forma que adquirió producto de la interacción entre los activis-

\footnotetext{
${ }^{35}$ Las Plazas se convirtieron en "espacios seguros" (Tilly, 2000) donde la policía no entraba, "lo tenían prohibido" (Comunicación personal activista de Madrid, 26/07/2012).
} 
tas, pero también, resultado de la actividad contenciosa. La creatividad de aquellos días se plasmó en carteles, mantas, dibujos, "tendederos" para colocar todo tipo de ideas de los visitantes (Comunicación personal activista de Barcelona, 06/07/2012), etc., todo ello formaba parte de la expresividad de los sueños y de la indignación de aquel momento.

Finalmente el momento de dejar la plaza llegó. La decisión conllevó en cada lugar un proceso lento y arduo, especialmente por el sistema de toma de decisiones, en Barcelona por cuotas y en Madrid por consenso absoluto. Algunos activistas recuerdan el poder de la plaza durante aquellas discusiones: "para mucha gente si no existía Sol desaparecía su enganche" (Comunicación personal activistas de Madrid, 13/07/2012 y 26/07/2012). En Barcelona se dio de la misma manera: "Para muchos el símbolo se convirtió en el objetivo" (Comunicación personal activista de Barcelona, 19/07/2012). De cualquier forma la decisión fue dejar la plaza e irse a los barrios. Un memorable cartel dejó el 15-M cuando abandonó Sol: "conocemos el camino de vuelta" (Comunicación personal activista de Madrid, 13/07/2012).

El significado de los lugares es importante dentro de la contienda política, tanto como "contextos y como apuestas" (Sewell, 2001: 64). Sewell (2001) distingue el significado original de los espacios del "sentido" (meaning) político que estos, convertidos en lugares, adquieren luego de las acciones de contienda. Esto nos recuerda el sentido de las plazas y el objetivo de la policía por "recuperarlas". En Barcelona el desalojo cristalizó el sentido político de la Plaça Catalunya, mientras en Madrid terminó por consolidarse durante el desalojo y protección que la policía hizo de "Sol" al desalojar el punto de información cuando la acampada ya no existía. Un activista de Madrid recuerda que aquella noche la policía había acordonado el sector y suspendido el acceso al metro y al tren: la policía había "tomado la plaza" (Comunicación personal activista de Madrid, 26/07/2012). Lugares como el Congreso de los Diputados en Madrid o el Parlament en Barcelona guardan un significado que se convierte en foco de atención en la actividad del movimiento 15-M. De Plaça Catalunya al Parlament y/o hasta la Generalitat era un recorrido habitual; en contraposición la policía acordonaba estos lugares para su resguardo. Lo mismo sucedió en Madrid, la Calle Alcalá, vía directa al Congreso, estuvo siempre vedada para el 15-M.

\section{Conclusión}

El movimiento 15-M repercutió en muchos aspectos y ámbitos del tejido social en el Estado español, especialmente a partir de cómo encaró la contienda política que protagonizó. Un aspecto fundamental de esto tuvo que ver con la ocupación del espacio público. La Puerta del Sol y la Plaça Catalunya se transformaron en un "sitio social", en los cuales surgió la actividad organizada de individuos y personas: redes dentro y más allá de las plazas. Se transformó el espacio física y simbólica- 
mente, pero a la vez, este espacio, en la medida en que transcurrió la contienda política, limitó o facilitó la dinámica cotidiana, la movilización, los objetivos del movimiento.

El 15-M es diverso, en ideas, identidades, sensibilidades y un largo etcétera. Lo que hemos encontrado en este trabajo, independientemente de la diversidad de ideas e identidades, es un proceso de "separación" sobre tales identidades al momento de exponerse éstas a grandes escalas espaciales y a una alta movilidad en las conexiones entre los sitios sociales a las que pertenecían. La amplitud del 15-M en todo el Estado (en nuestro caso la conexión entre Barcelona y Madrid) no implica suponer "románticamente" que los conflictos identitarios y las demandas que le acompañan hayan desaparecido; sin embargo, al haberse constituido sobre determinados valores y prácticas y al experimentar una amplitud y gran movilidad en sus conexiones hizo que emergiera una identidad ampliada que ha cobijado bajo la "indignación" a todo este movimiento.

Un aspecto relacionado con la identidad del 15-M es la variedad de repertorios de lucha que este movimiento utilizó. Entre ellos destacan, por un lado, el Internet y las diferentes modalidades de comunicación, $y$, por otro, la ocupación del espacio público como forma de protesta —en algunos casos conlleva la práctica de "acampar"- - La combinación de ambas cuestiones, junto con la variabilidad de las categorías espaciales, llevó a que la ocupación de una plaza y su uso como lugar de discusión política y protesta, se posicionara como un repertorio "aceptado" - o por lo menos disponible - dentro de los movimientos sociales y adquiriera "modularidad". Esto es más evidente si se piensa a nivel internacional. Un antecedente sería la plaza Tahrir en Egipto y un derivado Ocuppy Wall Street. Si lo vemos en continuum, de Tahrir a Wall Street, veremos un como un nuevo repertorio va adquiriendo "modularidad".

Tanto en la "separatividad" de las identidades como en la "modularidad" que adquiere el repertorio de acampar o tomar una plaza, hay un tránsito de mayor a menor proximidad, de menor a mayor movilidad. Este tránsito se explica por un mecanismo en especial: el de "correduría". Éste se expresa en la conexión entre sitios sociales anteriormente desconectados. En conjunto, el 15-M representa, tanto dentro de la plaza como fuera de ella, de manera ejemplar está práctica y ese significado.

Finalmente, algunos reconocen en "Sol" o en Plaça Catalunya (entre otras plazas también importantes) un símbolo de este movimiento. Éstas se consolidaron en su momento como una herramienta de lucha, un "sitio" donde se construía cotidianamente un discurso crítico sobre la crisis, la democracia y la política. Cuestión que las propias autoridades, políticos y medios de comunicación validaron, es decir, actuó en ello el mecanismo de "certificación" hacia el movimiento y las plazas. Cuestión que cambio posteriormente. Este significado no fue comparativamente mayor o menor en Madrid respecto de Barcelona - o viceversa-, pero si alguna de ellas adquirió por momentos una aparente centralidad esto se produjo como res- 
puesta al momento de la contienda, esto es, se produjo por el necesario vínculo entre el tiempo real de la contienda a un espacio concreto, pero nada más. Así mismo, cada uno de estos espacios permearon las identidades y los repertorios.

Por último, cada "sitio social" conformado por y en medio de una contienda requiere de un "signo-símbolo" por el que se reconoce, por el que se nombra y, en este sentido, es por lo que no sólo, aún hoy, "Sol" sigue siendo un punto central para las manifestaciones del 15-M en Madrid, sino que sigue estando presente en las webs, carteles y propaganda de todos los 15-M: ha pasado, pues, a ser el "sitiosigno" emblema. En cualquier caso, ya no importa si es una plaza o qué plaza concreta sea, lo necesario es "tomar", tomar el espacio público ${ }^{36}$. Las plazas tienen un nuevo "sentido" político, resultado de la apropiación por los activistas y de la contienda política (luego de desalojos, campañas de desprestigio, etc.). Sin embargo, tampoco cabe obviar que las plazas, sea "Sol" o Plaça Catalunya, para la mayoría de la gente siguen siendo lugares de encuentro y de consumo ${ }^{37}$, pensarlas como enclaves de ciudadanía o de organización política es subversivo: "Estábamos reclamando el espacio público para volver a empoderarnos" sobre "las decisiones sobre el espacio, y no hablo solo de una plaza sino de los recursos públicos también" (Comunicación personal activista de Barcelona, 06/07/2012).

\section{Bibliografía}

Aguilar, Salvador (2008a) "Después de la crisis del movimiento obrero: el conflicto social en la era de la globalización”. Ponencia presentada al Congreso de Ciencia Política Crítica, organizado en Bilbao por la UPV en noviembre de 2008.

Aguilar, Salvador (2008b) Las relaciones constituyen las unidades sociales básicas. En la muerte de Charles Tilly. Barcelona: Editorial Hacer.

Aguilar, Salvador, et al. (2012) "Movimientos ciudadanos al rescate", en S. Aguilar (ed.) Anuario del Conflicto Social 2011. Barcelona: Observatorio del Conflicto Social.

Aguilar, Salvador, et al. (2003) Una nova societat civil: Accions col-lectives de masses a l'Espanya postransicional (ca. 1982-2002). [Deposito digital Univer-

\footnotetext{
${ }^{36}$ Durante la acampada el tomar el espacio público sucedió no solo en las plazas de las que hemos venido hablando, también se tomaron otros espacios cercanos a las acampadas. Así también, se tomaron edificios públicos, se "acampó" (otra forma de tomar) frente a los hospitales, se tomaron los bancos como forma de denuncia ante los desahucios.

${ }^{37}$ Unos meses después de la acampada en Barcelona las autoridades de la ciudad colocaron en Plaça Catalunya una pista gigante de hielo, acudían diariamente miles de personas a patinar, el ambiente era otro, de frialdad total.
} 
sidad de Barcelona. URL: <http://hdl.handle.net/2445/12622>. Visitado el 31 de julio de 2012].

Andreu, Marc (2012) "El 2011 a pie de calle: de la red a la plaza", en P. Ibarra y M. Cruells (coords.) Nuevas movilizaciones en la red. Anuario de Movimientos Sociales 2011. Abadiño: Fundación Betiko.

Andreu, Marc (2009) "Acumulación de fuerzas desde la memoria histórica" en Pedro Ibarra y Marta Cruells (coord.) Jóvenes en la red. Anuario de Movimientos Sociales 2009. Abadiño: Fundación Betiko.

Andreu, Marc (2008) "En crisis y a la búsqueda de otra comuna de París" en Pedro Ibarra y Marta Cruells (coord.) Crisis y respuestas en la red. Anuario de Movimientos Sociales 2008. Abadiño: Fundación Betiko.

Andreu, Marc (2007). "Nueva cultura del territorio y renovada acción política desde la ciudadanía" en Pedro Ibarra y Marta Cruells (coord.) La red en la ciudad. Anuario de Movimientos Sociales 2007. Abadiño: Fundación Betiko.

Andreu, Marc (2006) "Movimiento vecinal en 2006: vivienda digna, participación ciudadana e incidencia política de un actor social", en P. Ibarra y M. Cruells (coords.) La red en conflicto. Anuario de Movimientos Sociales 2006. Abadiño: Fundación Betiko.

Andréu Abela, Jaime; García-Nieto Gómez-Guillamón, Antonio, y Pérez Corbacho, Ana $\mathrm{M}^{\mathrm{a}}$ (2007) Evolución de la Teoría Fundamentada como técnica de análisis cualitativo. Madrid: CIS (Cuadernos Metodológicos 40).

Auyero, Javier (2002) "La geografía de la protesta". Trabajo y Sociedad. Indagaciones sobre el empleo, la cultura y las prácticas políticas en sociedades segmentadas (Santiago del Estero, Argentina), III (4). [URL: $<$ http://www.unse.edu.ar/trabajoysociedad/AuyeroEspacial.htm>. Visitado el 16 de junio 2012].

Blee, Kathleen, y Taylor, Verta (2002) "Semi-structured interviewing in social movement research", en B. Klandermans y S. Staggenborg (eds.) Methods of social movement research. Minneapolis: University of Minnesota Press.

Bringel, Breno, et al. (2006) "Las «venas abiertas» en 2006", en Pedro Ibarra y Marta Cruells (coord.), La red en conflicto. Anuario de Movimientos Sociales 2006. Biskaia: Fundación Betiko.

Calle, Ángel (2011) "Dilemas alrededor del 15-M". Publico.es, 23 de Julio. [URL: $<$ http://blogs.publico.es/dominiopublico/category/angel-calle-collado/>. Visitado el 15 de julio del 2012].

Castells, Manuel (2012) “Autocomunicación de masas y movimientos sociales en la era del internet”, en S. Aguilar (ed.) Anuario del Confilcto Social 2011. Barcelona: Observatorio del Conflicto Social, Universidad de Barcelona.

Castells, Manuel (2011a) “\#Wikiacampadas”, La Vanguardia, 28/05/2011. [URL: $<$ http://www.lavanguardia.com/opinion/articulos/20110528/54160922879/wikia campadas.html $>$. Visitado el 10 de agosto del 2011]. 
Castells, Manuel (2011b) "Después de la acampada", La Vanguardia, 18/06/2011. [URL: $<$ http://www.lavanguardia.com/opinion/articulos/20110618/54173451006 /despues-de-la-acampada.html>. Visitado el 10 de agosto del 2011].

Castells, Manuel (1986) La ciudad y las Masas. Sociología de los movimientos sociales urbanos. Madrid: Alianza Editorial.

CIS (2012) Nota de investigación sobre estudio cualitativo: "Representaciones políticas y Movimiento 15M". Estudio $\mathrm{n}^{\mathrm{0}}$ 2921. [URL: $<$ http://www.cis.es/cis/opencms/ES/12_NotasInvestigacion/Investigaciones/201 2/NotaInvestigacion0008.html>. Visitado el 15 de julio del 2012].

Cortavitarte Carral, Emili (2011) "Balance del 2011: mucho paro, más contrareformas y el movimiento obrero en retroceso", en P. Ibarra y M. Cruells (coords.) Nuevas movilizaciones en la red. Anuario de Movimientos Sociales 2011. Abadiño: Fundación Betiko.

Cortavitarte Carral, Emili (2010) "El agridulce sabor de la derrota, a pesar de la huelga general del 29 S", en P. Ibarra y M. Cruells (coords.) Las otras redes. Anuario de Movimientos Sociales 2010. Abadiño: Fundación Betiko.

De la Rubia, Rafael, et al. (2011) Hacia una revolución mundial no-violenta: del 15M al 15O. Madrid: Editorial Manuscritos.

Ezquerra, Sandra (2012) "Discursos y prácticas feministas en el movimiento 15-M: avances y asignaturas pendientes" en Pedro Ibarra y Marta Cruells (coord.), Nuevas movilizaciones en la red. Anuario de Movimientos Sociales 2011. Abadiño: Fundación Betiko

Ezquerra, Sandra (2011) "El 15M ha logrado sacar a la calle miles de personas que no se levantaban del sofá". La Vanguardia, 10 de Junio [URL: $<$ http://www.lavanguardia.com/politica/20110610/54167886053/sandraezquerra-el-15m-ha-logrado-sacar-a-la-calle-miles-de-personas-que-no-selevantaban-del.html>. Visitado el 15 de julio del 2012].

Fernández, Joseba (2011) Las movilizaciones del 15-M han sido exitosas. ¿Le alcanzarán las fuerzas para sostener su proceso? Centro de Estudios sobre Movimientos Sociales, UPF [Puesto en línea el 01/07/2011. URL: $<$ http://cemsenmoviment.wordpress.com/2011/07/01/las-movilizaciones-del-15$\mathrm{m}$-han-sido-exitosas- $\% \mathrm{C} 2 \%$ BFle-alcanzaran-las-fuerzas-para-sostener-suproceso/>. Visitado el 15 de julio del 2012].

Foucault, Michel (1999) "Los Espacios Otros". Revista Versión. Estudios de comunicación y política (U. Autónoma Metropolitana, México D.F.), 9, 15-26. [URL: $<$ http://148.206.107.15/biblioteca_digital/estadistica.php?id_host=6\&tipo=ARTI CULO\&id=1932\&archivo=7-132-1932qmd.pdf\&titulo=Espacios\%20otros $>$. Visitado el 12 de octubre de 2012]. [Conferencias pronunciada en el Centre d' Éstudes architecturales el 14 de marzo de 1967 y publicada en Architecture, Mouvement, Continuité, 5, octubre de 1984, 46-49].

García-Rosales, Cristina, y Penella Heller, Manuel (2011) Palabras para indignados. Hacia una nueva revolución humanista. Madrid: Mandala Ediciones. 
Giner, Salvador (2012). "El combate cívico y sus rebeldes primitivos", en S. Aguilar (ed.) Anuario del conflicto social 2011. Barcelona: Observatorio del Conflicto Social, Universidad de Barcelona.

Giddens, Anthony (1995) La constitución de la sociedad: bases para la teoría de la estructuración. Buenos Aires: Amorrortu.

Harvey, David (1998) La Condición de la posmodernidad: investigación sobre los orígenes del cambio cultural. Buenos Aires: Amorrortu.

Ibarra, Pedro, y Grau, Elena (2007) "Presentación / En busca de la identidad perdida", en P. Ibarra y M. Cruells (coords.) La red en la ciudad. Anuario de Movimientos Sociales 2007. Abadiño: Fundación Betiko.

Iglesias, Pablo (2005) "Días de disidencia. Geografía de las protestas contra el G-8 en Escocia". Ponencia presentada al VII Congreso de la Asociación Española de Ciencia Politica y de la Administración, celebrado en Madrid.

Lefebvre, Henri (1991) The Production of Space. (Trad. por D. Nicholson-Smith). Cambridge (MA): Blackwell.

López, Sara, et al. (2005) "Redes sociales en 2005: Tras la tempestad ¿vendrá el repliegue?", en P. Ibarra y M. Cruells (coords.) La red en la encrucijada. Anuario de Movimientos Sociales 2005. Abadiño: Fundación Betiko.

McAdam, Doug (2002) "Movimientos «iniciadores» y «derivados»: procesos de difusión en los ciclos de protesta", en M. Traugott (ed.) Protesta social: repertorios y ciclos de la acción colectiva. Barcelona: Editorial Hacer.

McAdam, Doug; McCarthy, John D., y Zald, Mayer (1999) Movimientos Sociales: perspectivas comparadas. Oportunidades Políticas, Estructuras de movilización y Marcos interpretativos culturales. Madrid: Istmo.

McAdam, Doug; Tarrow, Sidney, y Tilly, Charles (2005) Dinámica de la contienda política. Barcelona: Editorial Hacer.

Martí i Puig, Salvador (2011) "Pienso luego estorbo; España entre la crisis y la indignación", en P. Ibarra y M. Cruells (coords.) Nuevas movilizaciones en la red. Anuario de Movimientos Sociales 2011. Abadiño: Fundación Betiko.

Martin, Deborah, y Miller, Byron (2003) "Space and Contentious Politics". Mobilization. An International Journal, 8 (2), 143-156.

Marston, Sallie (2003) "Mobilizing Geography: Locating Space in Social Movement Theory". Mobilization: An International Journal. 8 (2), 227-233.

Massey, Doreen (1984) Geography matters! London: Cambridge University Press.

Melucci, Alberto (1994) "Qué hay de nuevo en los nuevos movimientos sociales?", en E. Laraña y J. Gusfield (eds.) Los nuevos movimientos sociales: de la ideología a la identidad. Barcelona: CIS, 119-150.

Mora, Félix (2011) "Pensar el 15-M", en F. Rodrigo Mora, E. Prado Esteban y F. G. Rubio. Pensar el 15-My otros textos. Madrid: Editorial Manuscritos.

Morán, María Luz (2005) "Viejos y nuevos espacios para la ciudadanía: la manifestación del 15 de febrero en Madrid". Política y Sociedad, 2005, 42 (2), 95-113. 
Navarro, Vicenç (2011) "El Partido Popular y la clase trabajadora española". Rebelión. [Puesto en línea el 19/11/2011. URL: $<$ http://www.rebelion.org/noticias/2011/11/139633.pdf $>$. Visitado el 24 de julio de 2012].

Observatorio Metropolitano (2011) La crisis que viene. Madrid: Editorial Traficantes de Sueños.

Oslender, Ulrich (2002) "Espacio, Lugar y Movimientos sociales: hacia una «espacialidad de resistencia»". Scripta Nova, Revista electrónica de Geografía y Ciencias Sociales, VI (115) [Puesto en línea en junio de 2002. URL: $<$ http://www.ub.edu/geocrit/sn/sn-115.htm>. Visto el 16 de junio de 2012].

Pastor, Jaime (2012) "La emergencia del movimiento 15-M en Madrid, un nuevo actor sociopolítico", en S. Aguilar (eds.) Anuario del conflicto social 2011. Barcelona: Observatorio del Conflicto Social, Universidad de Barcelona, 175-191.

Pradel, Marc, et al. (2005) "La última oleada de movilizaciones 2002-2004", en E. Grau y P. Ibarra (comps.) La politica en la red: anuario de movimientos sociales 2005. Barcelona: Icaria.

Pradel, Marc, et al. (2004) "La última oleada de movilizaciones (2002-2004)", en P. Ibarra y M. Cruells (comps.) La política en la red. Anuario de Movimientos Sociales 2004. Biskaia: Fundación Betiko.

Sewell, Jr., William (2001) "Space in Contentious", en R. Aminzade (ed.) Silence and Voice in the Study of Contentious Politics. Cambridge (RU): University of Cambridge.

Soja, Edward (1989) Postmodern Geographies: The Reassertion of Space in Critical Social Theory. London and New York: Verso.

Taibo, Carlos (2011a) Nada será como antes. Sobre el movimiento 15-M. Madrid: Catarata.

Taibo, Carlos (2011b) "El futuro del movimiento 15-M". Rebelión [Puesto en línea el 27/05/2011. URL: <http://www.rebelion.org/noticia.php?id=129221>. Visitado el 15 de julio del 2012].

Tarrow, Sidney (2002) "Ciclos de acción colectiva: entre los momentos de locura y el repertorio de contestación", en M. Traugott (ed.) Protesta social: repertorios y ciclos de la acción colectiva. Barcelona: Editorial Hacer, 99-129.

Tilly, Charles (2007) Violencia colectiva. Barcelona: Editorial Hacer.

Tilly, Charles (2003) "Contention over Space and Place". Mobilization: An International Journal, 8 (2), 221-225.

Tilly, Charles (2002) "Repertorios de acción contestataria en Gran Bretaña, 17581834", en M. Traugott (ed.) Protesta social: repertorios y ciclos de la acción colectiva. Barcelona: Editorial Hacer.

Tilly, Charles (2000) "Spaces of Contention". Mobilization: An International Journal, 5 (2), 135-159. 
Trinidad, Antonio; Carrero, Virginia, y Soriano, Rosa $\mathrm{M}^{\mathrm{a}}$ (2006) Teoría fundamentada "Grounded Theory". La construcción de la teoría a través del análisis interpersonal. Madrid: CIS (Cuadernos metodológicos 37).

Viejo Viñas, Raimundo (2011) "Las tres eras de la democracia". La Vanguardia, 12/06/2011 [URL: <http://www.lavanguardia.com/opinion/temas-dedebate $/ 20110612 / 54169365336 /$ es-posible-otra-democracia.html?page $=2>$. Visitado el 15 de julio del 2012].

\section{Fuentes periodísticas:}

"El 15M y la promesa de la política". El Pais, 15/05/2012.

"A spring of frustration in Spain". Washington Post, 19/05/2011.

"Desalojo en Plaza Cataluña". El Mundo.es, 31/05/2011.

"22.000 personas se reúnen previo a la jornada de reflexión en Madrid”. El País, $21 / 05 / 2011$.

"Retrato de un presidente en 20 Leyes". El País, 03/04/2011.

"Los hitos políticos de Zapatero". Público.es, 02/04/2011.

"La tasa de paro se instala en el 20\% al cierre del 2010". El País, 28/01/2011.

"La reforma de las pensiones". La Vanguardia, 28/01/2011.

"Los trabajadores tendrán que cotizar 38 años y medio para jubilarse a los $65 " . E l$ Pais, 27/01/2011.

"El congreso rechaza la pretensión del PP de anula la subida del IVA prevista para julio". El Economista.es, 16/03/2010.

"Las medidas de ajuste del gasto y reducción del déficit público". TV Cuatro, $12 / 05 / 2010$.

"Zapatero repite victoria con más fuerza". El País, 10/03/2008.

"Zapatero dice que el diálogo social en esta legislatura ha posibilitado el periodo con menos huelgas". El economista.es, 23/10/2007.

"Zapatero defiende su política de inmigración y seguridad con críticas a la herencia de Rajoy". El Pais, 31/05/2006.

"Aprobada la ordenanza cívica que debe regular la prostitución, la mendicidad y la venta ambulante en Barcelona". La Vanguardia, 23/12/2005. 